\title{
Monocyte Transmodulation: The Next Novel Therapeutic Approach in Overcoming Ischemic Stroke?
}

\author{
Joohyun Park ${ }^{1,2 \dagger}$, Ji Young Chang ${ }^{1,2+}$, Jong Youl Kim ${ }^{1}$ and Jong Eun Lee ${ }^{1,2,3 *}$ \\ ${ }^{1}$ Department of Anatomy, Yonsei University College of Medicine, Seoul, South Korea, ${ }^{2}$ Brain Korea 21 Plus Project for \\ Medical Science, Yonsei University College of Medicine, Seoul, South Korea, ${ }^{3}$ Brain Research Institute, Yonsei University \\ College of Medicine, Seoul, South Korea
}

The immune response following neuroinflammation is a vital element of ischemic stroke pathophysiology. After the onset of ischemic stroke, a specialized vasculature system that effectively protects central nervous system tissues from the invasion of blood cells and other macromolecules is broken down within minutes, thereby triggering the inflammation cascade, including the infiltration of peripheral blood leukocytes. In this series of processes, blood-derived monocytes have a significant effect on the outcome of ischemic stroke through neuroinflammatory responses. As neuroinflammation is a

OPEN ACCESS

Edited by: Johannes Boltze,

University of Warwick, United Kingdom

Reviewed by:

Slava Rom

Temple University, United States Sudhanshu P. Raikwar,

University of Missouri, United States

${ }^{*}$ Correspondence: Jong Eun Lee jelee@yuhs.ac

†These authors share first authorship

Specialty section:

This article was submitted to

Stroke,

a section of the journa

Frontiers in Neurology

Received: 01 July 2020 Accepted: 22 September 2020

Published: 22 October 2020

Citation:

Park J, Chang JY, Kim JY and Lee JE (2020) Monocyte Transmodulation:

The Next Novel Therapeutic Approach

in Overcoming Ischemic Stroke?

Front. Neurol. 11:578003.

doi: 10.3389/fneur.2020.578003 necessary and pivotal component of the reparative process after ischemic stroke, understanding the role of infiltrating monocytes in the modulation of inflammatory responses may offer a great opportunity to explore new therapies for ischemic stroke. In this review, we discuss and highlight the function and involvement of monocytes in the brain after ischemic injury, as well as their impact on tissue damage and repair.

Keywords: ischemic stroke, neuroinflammation, monocytes, monocyte conversion, macrophages

\section{INTRODUCTION}

Stroke is the third leading cause of death globally, and $\sim 80 \%$ of all strokes are ischemic strokes, which occur when brain cells die of reduced blood supply to various parts of the brain (1-3). Within minutes after the onset of stroke, immune processes are activated by ischemic cascades, from intravascular events triggered by the occlusion and moving of vessels to brain parenchymal inflammatory responses, leading to tissue damage and repair (4-10). The pathophysiological features of ischemic stroke, such as the production of reactive oxygen species (ROS) (11), the release of ATP and UTP by dying cells (12), and the loss of beneficial nitric oxide (NO) in states of oxidative stress (13), can trigger the activation of a neuroinflammatory response (14-17). In addition, cells that are dying of a lack of blood supply release cytokines, chemokines, and matrix metalloproteinases, thereby inducing the infiltration of blood cells, such as monocytes, lymphocytes, neutrophils, and natural killer cells, into the injured brain parenchyma (18-20). The initial immune response to neuroinflammation following ischemic stroke is characterized by early neutrophils swarming into the ischemic injured brain. Neutrophils' immune process has been extensively studied and is well-organized, with subsequent steps of cellular recruitment (21-25). However, little is known about the impact of monocyte recruitment to brain tissue affected by ischemic injury.

In mice, monocytes are categorized into two functional subpopulations, which can be differentiated by the expression of specific surface markers, such as lymphocyte antigen 6C (Ly6C), C-C chemokine receptor 2 (CCR2), and CX3C chemokine receptor (CX3CR1) (26). The first 
subset is characterized as short-lived and pro-inflammatory, with active recruitment to inflamed tissues by circulating through the blood; this subpopulation expresses $\mathrm{Ly} 6 \mathrm{C}^{+} \mathrm{CCR} 2^{\text {high }} \mathrm{CX} 3 \mathrm{CR} 1^{\text {low }}$ markers (27). The second subset is known for alternative and non-classical activation, and it is characterized by an antiinflammatory phenotype and CX3CR1-dependent recruitment to local non-inflamed tissues; this subpopulation expresses Ly6C ${ }^{-}$CCR $2{ }^{\text {low }}$ CX3CR $1^{\text {high }}$ markers (28-30). Blood monocytes have plasticity and are embroiled in pro-inflammatory and antiinflammatory responses in various diseases $(28,31-34)$. Blood monocytes are a heterogeneous population of circulating leukocytes. The classical pro-inflammatory monocytes $\left(\mathrm{Ly} 6 \mathrm{C}^{+} \mathrm{CCR} 2{ }^{\text {high }} \mathrm{CX} 3 \mathrm{CR} 1^{\text {low }}\right.$ ) are rapidly recruited to inflamed tissues and release high levels of inflammatory cytokines, such as tumor necrosis factor- $\alpha$ (TNF- $\alpha$ ) (35), interleukin-1 $\beta$ (IL-1 $\beta$ ) (36), and IL-6 (37), when there is tissue damage. Further, these monocytes may turn into tissue macrophages (38). On the contrary, the alternative non-classical monocytes $\left(\right.$ Ly6C ${ }^{-}$CCR $2{ }^{\text {low }} \mathrm{CX} 3 \mathrm{CR} 1^{\text {high }}$ ) play a crucial role in reparative processes, producing anti-inflammatory cytokines, such as IL-4, IL-10 (39), and IL-13 (40), in inflammatory environments. Alternative monocytes can also turn into alternative macrophages (41-44). These two distinct subsets of monocytes are known to be polarized into M1 (pro-inflammatory) (45) or M2 (anti-inflammatory) (46) macrophages, thereby influencing the local milieu at different time points following tissue damage (47-49).

Given that the immune response comprises numerous cell populations that influence the neuroinflammatory process at different times, detailed analytical studies of infiltrating monocytes are needed. In this review, we summarize the precise roles of infiltrating blood monocytes on neuroinflammation following ischemic stroke, highlighting how the distinct subsets of monocytes work in beneficial and noxious ways. Efforts to understand the mechanisms of monocytes in neuroinflammation following ischemic stroke may not only help address the limitations of current stroke therapies, but also suggest novel treatment strategies for stroke through the modulation of immune cells.

\section{DEVELOPMENT AND MIGRATION OF MONOCYTES}

Monocytes are distinct myeloid components of an organism's innate immune system, and they are heavily involved in organisms' neuropathological processes $(50,51)$. The development of classical Ly6C $\mathrm{C}^{+}$monocytes begins when they are derived from hematopoietic stem cells (HSCs) in the bone marrow (BM); depending on the macrophage colony-stimulating factor (M-CSF), the development of blood monocytes may vary $(52,53)$. Once $\mathrm{Ly}_{6} \mathrm{C}^{+}$monocytes egress in the blood, they are considered incompletely differentiated cells, which have a high degree of developmental plasticity (54). These highly adjustable monocytes differentiate into phagocytic macrophages as they promptly drift toward inflamed tissues after sensing environmental stimuli following injury (55-57). In addition, in a steady state, circulating $\mathrm{Ly}_{6} \mathrm{C}^{+}$pro-inflammatory monocytes are the precursors of the $\mathrm{Ly}^{-} \mathrm{C}^{-}$monocytes patrolling the vasculature in the blood and BM (58). Furthermore, the differentiation and development of monocyte subpopulations are affected by numerous factors, including Kruppel-like factor 4 (KLF4) (59). Alder et al. investigated the consequences of KLF4 function loss for monocytes; the producibility of $\mathrm{CD} 115^{+} \mathrm{Gr}^{+}$ monocytes, the Ly6C ${ }^{+}$monocytes, was thoroughly reduced by the transplantation of $\mathrm{KLF}^{-/}$- fetal liver cells into wild-type mice, which were subjected to lethal irradiation (59). CCR2 (60) and its agonists, monocyte chemoattractant protein 1 (MCP-1) (also known as CCL2) and MCP-3 (also known as CCL7), play a central role in the migration of $\mathrm{Ly} 6 \mathrm{C}^{+}$monocytes from BM to blood. The number of these classical monocytes was significantly decreased in the bloodstream, although it was significantly higher in CCR2 knockout mice compared to wild-type mice. Tsou et al. demonstrated that CCR2 ligands, MCP-1 and MCP-7, are some of the most necessary chemokines for proper control of monocyte levels (60). In addition, many studies regarding CCR2 signaling and chemokines related to Ly6C ${ }^{+}$monocytes have been conducted for various diseases, suggesting that classical monocytes play a pivotal role in immune responses (61-64). By utilizing chromatin immunoprecipitation sequencing and gene expression profiling, researchers revealed that transcription factor KLF4 is a powerful indirect target gene of interferon regulatory factor (IRF8) (65). In addition, the differentiation of $\mathrm{Ly} \mathrm{C}^{+}$monocytes was not observed in IRF8 ${ }^{-/-}$mice, suggesting that the IRF8-KLF4 axis is the key modulator in monocyte development (65). Transcription factor PU.1 (encoded by the Spi1 gene), one of the erythroblast transformation-specific family transcription factors, is essential for transcriptional regulation in the development of the myeloid lineage (66). PU.1 is highly expressed in monocytes and macrophages (67). During monopoiesis, PU.1 promotes IRF8 expression in monocytic dendritic progenitors, whereas IRF8 directly binds to the promoter region of the Klf4 gene in common monocyte progenitors (cMoPs), resulting in the differentiation of $\mathrm{Ly}^{+} \mathrm{C}^{+}$monocytes (68). Hanna et al. investigated nuclear receptor subfamily 4 group A member 1 (Nr4a1, Nur77) (69), and by analyzing the monocyte population, they showed that $\mathrm{Ly}^{-} \mathrm{C}^{-}$monocytes exhibit apoptosis in the $\mathrm{BM}$ of $\mathrm{Nr} 4 \mathrm{al}^{-/-}$mice. Additionally, as shown through a series of adoptive transfer studies by Hanna et al., the conversion of $\mathrm{Nr} 4 \mathrm{a} 1^{-/-} \mathrm{Ly}^{-1} \mathrm{C}^{+}$monocytes to $\mathrm{Ly}^{-} \mathrm{C}^{-}$monocytes is aborted in the BM, blood, and tissues. This suggests that not only is Nr4a1 vital for $\mathrm{Ly}^{-} \mathrm{C}^{-}$monocyte survival, but also differentiation of $\mathrm{Ly} 6 \mathrm{C}^{-}$monocytes from $\mathrm{Ly}^{-} \mathrm{C}^{+}$monocytes is also crucial (69). Regarding transcription factor CCAAT enhancer-binding protein $\beta(\mathrm{C} / \mathrm{EBP} \beta)$, Mildner et al. confirmed that the two monocyte subsets were originally homogenous populations in the $\mathrm{BM}$ by transcriptome and epigenome profiling assays. However, heterogeneity of Ly6 $\mathrm{C}^{\text {int }}$ monocytes in the blood, where the generation of $\mathrm{Ly}^{-} \mathrm{C}^{-}$monocytes arising from $\mathrm{Ly} \mathrm{C}^{+}$monocytes depends on $\mathrm{C} / \mathrm{EBP} \beta$, is involved in regulating $\mathrm{Ly}^{-}$monocyte survival factor $\mathrm{Nr} 4 \mathrm{al}$ (70) (Figure 1). 


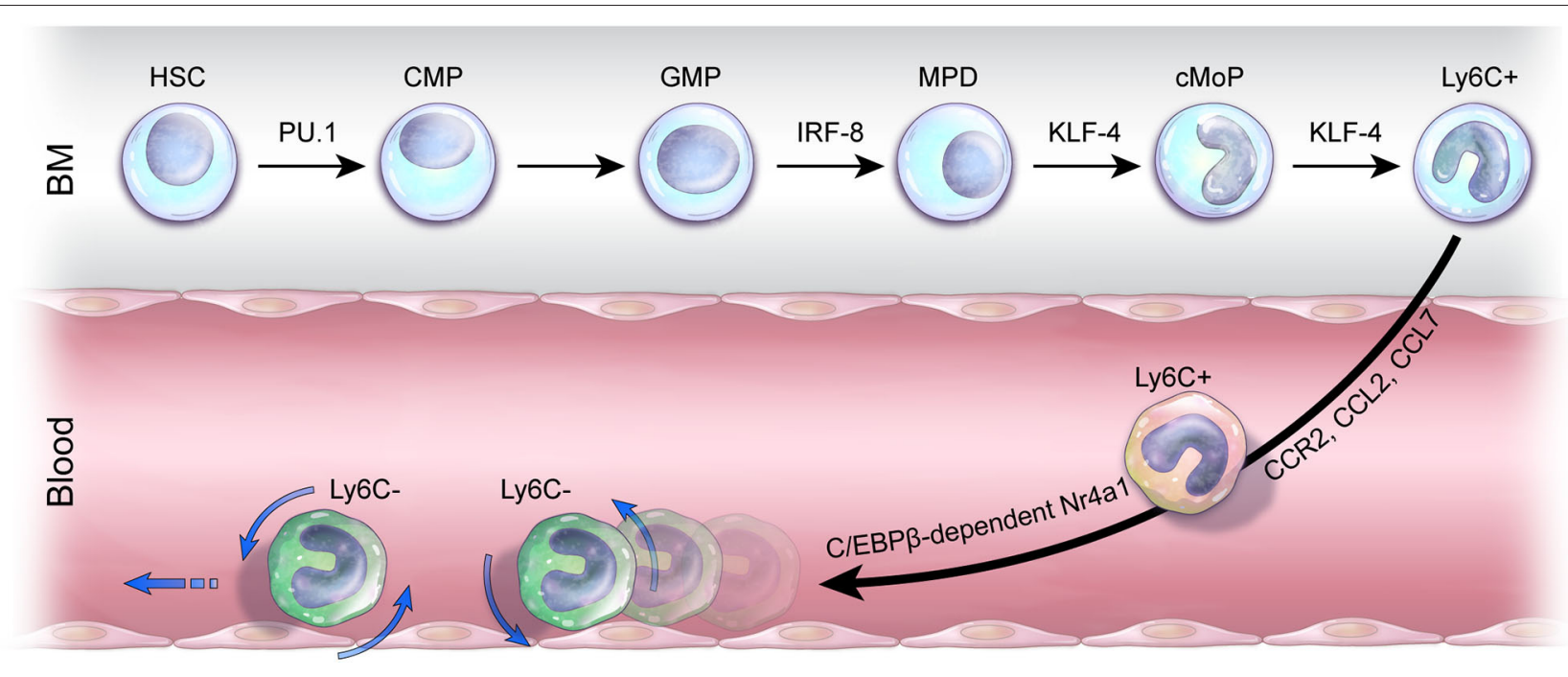

FIGURE 1 | Monocyte development and mobilization. In the bone marrow (BM), pro-inflammatory Ly6C ${ }^{+}$monocytes are derived from cMoPs that are differentiated from a series of hematopoietic stem cells (HSCs) by transcription factors PU.1, interferon regulatory factor 8 (IRF8), and Kruppel-like factor 4 (KLF4). Ly6C ${ }^{+}$ monocytes emigrate out of the BM in a C-C chemokine receptor 2 (CCR2)-dependent manner, and the ligands of CCR2, C-C motif ligand 2 (CCL2) and C-C motif ligand 7 (CCL7), stimulate Ly6 $\mathrm{C}^{+}$monocyte mobilization into the blood. The development of anti-inflammatory Ly6 $\mathrm{C}^{-}$monocytes from Ly6 $\mathrm{C}^{+}$monocytes depends on CCAAT enhancer-binding protein $\beta$ (C/EBP $\beta$ )-dependent nuclear receptor subfamily 4 group A member 1 (NR4A1). Ly6C- monocytes crawling on the endothelium in the periphery act in an immune surveillance capacity to maintain homeostasis.

\section{FUNCTIONAL HETEROGENEITY OF MONOCYTE SUBSETS IN MICE AND HUMANS: THE VITAL ROLE OF MICRORNA LEVEL DETECTION}

Monocytes, which consist of leukocytes circulating through the blood, are a heterogeneous population and a critical component of an organism's innate immune response against inflammation $(14,71)$. Although murine monocytes are often seen as dichotomous, monocytes in humans are divided into three distinct subsets, which are differentiated by the expression levels of CD14 (lipopolysaccharide receptor complex component) and CD16 (FC $\gamma$ RIII immunoglobulin receptor): (1) $\mathrm{CD} 14^{++} \mathrm{CD} 16^{-}$(classical), (2) $\mathrm{CD} 14^{+} \mathrm{CD} 16^{+}$ (intermediate), and (3) $\mathrm{CD} 14^{+} \mathrm{CD} 16^{++}$(non-classical) (72). When comparing murine and human monocytes, the classical and non-classical monocytes in humans are analogous to the $\mathrm{Ly}_{6 \mathrm{C}} \mathrm{C}^{+}$monocytes expressing CCR 2 high $\mathrm{CX} 3 \mathrm{CR} 1^{\text {low }}$ and Ly6C ${ }^{-}$CCR $2^{\text {low }}$ CX3CR $1^{\text {high }}$ in mice (73). The third subset of monocytes in humans, the intermediate monocytes, is not comparable to any in mice and are thought to be in the middle stage of classical monocytes transitioning into non-classical monocytes $(74,75)$.

MicroRNAs (miRNAs), which are small non-coding RNAs, bind to specific messenger RNAs (mRNAs) and inhibit the translation or promote the degradation of mRNAs (76). They play a vital role in regulating monocyte development and function (77). From the extensive list of miRNAs, the miRNA investigated first and foremost for monocytes is miRNA-146a, which regulates the functional heterogeneity of monocyte subsets
(78) and shows the largest difference in expression levels between $\mathrm{Ly}_{6} \mathrm{C}^{+}$and $\mathrm{Ly}_{6} \mathrm{C}^{-}$monocytes. Steady-state expression of miRNA146a is higher in Ly6C $\mathrm{C}^{-}$monocytes than in Ly6C ${ }^{+}$ monocytes in mice. In addition, miRNA-146a depletion induces abnormal myeloproliferation and myelodifferentiation of HSCs (79) and augments the pro-inflammatory responses of Ly6C $\mathrm{C}^{+}$ monocytes without affecting the change of monocyte subset development (78). Through miRNome data analysis, differences in miRNA expression were quantified between classical and non-classical monocytes in humans. miRNA-17, miRNA-18a/b, miRNA-19b, miRNA-20b, and miRNA-106a were overexpressed in classical monocytes, whereas miRNA-132, miRNA-146a, and miRNA-342-3p were overexpressed in non-classical monocytes (80). Moreover, it was reported that different motility of monocyte subsets (81) is associated with the expression of miRNA-19a. Dang et al. showed that knockdown of miRNA-19a markedly blocked the movement of $\mathrm{CD} 16^{-}$monocytes, known as classical monocytes, suggesting that miRNA-19a plays a crucial role in promoting $\mathrm{CD}^{-} 6^{-}$monocytes motility (82). Further research also revealed that pre-miRNA-432 overexpression, which is one of the miRNA candidates selected by in silico analysis, induces apoptosis of $\mathrm{CD}^{-} 6^{-}$monocytes, and the expression of miRNA-432 was significantly different between $\mathrm{CD} 16^{-}$and $\mathrm{CD} 16^{+}$monocytes. This suggests that miRNA- 432 regulates the apoptosis of $\mathrm{CD}^{-} 6^{-}$monocyte. In addition, Zawada et al. reported 38 miRNAs were differentially expressed in an intermediate subset of monocytes in humans, among which miRNA-150 was significantly downregulated in intermediate monocytes compared with both classical and non-classical monocyte subsets (83). 
Recently, Chipont et al. reported that the number of $\mathrm{Ly}^{-} \mathrm{C}^{-}$ monocytes in the blood, BM, and spleen is significantly reduced in $\mathrm{ApoE}^{-/-}$miRNA-21-deficient mice, resulting in the acceleration of the pro-inflammatory response in atherosclerosis. The study suggests that miRNA-21 inhibition in monocytes could be a plausible therapeutic approach in atherosclerosis (84). In addition, Selimoglu-Buet et al. revealed that miRNA150 is a critical component in regulating the generation of the Ly6C $\mathrm{C}^{-}$monocyte subset in mice and humans (85). The authors demonstrated that unrepressed expression levels of the Tet methylcytosine dioxygenase 3 (Tet3) gene led to a decrease in the levels of Ly6C $^{-}$monocytes in miRNA-150-deficient mice, highlighting the clinical implications that diminished expression of miRNA-150 mostly found in the peripheral blood $\mathrm{CD}_{14}{ }^{+}$monocytes of patients with chronic myelomonocytic leukemia. Given the studies discussed above, the detection of various miRNA levels in monocytes is needed to expand our knowledge of monocyte heterogeneity and develop new strategies to ameliorate monocyte-related diseases (Table 1).

\section{THE FUNCTION OF MICROGLIA AND MONOCYTE-DERIVED MACROPHAGES: THE IMPACT ON NEUROINFLAMMATION FOLLOWING ISCHEMIC STROKE}

\section{Microglia}

Microglia, or resident tissue macrophages in the central nervous system (CNS), which account for 5 to $20 \%$ of the glial cell population (86), contribute to tissue homeostasis by interacting with neurons and surveilling the microenvironment of the brain under a steady state (87). Upon an ischemic cascade, microglia react to the danger signal and are rapidly activated within minutes after the onset of ischemic stroke. Following ischemic stroke, microglial proliferation peaks between 2 and 3 days after the onset of the injury and lasts for several weeks. Microglia are rapidly activated and can phagocytose cell debris (clear apoptotic cells) (88). Activated microglia have both beneficial and detrimental effects. From the beneficial point of view, microglial depletion caused by the administration of dual colony-stimulating factor 1 (CSF1)/c-kit inhibitor, PLX3397, may exacerbate post-ischemic neuroinflammation in the brain. In mice, microglial depletion can augment leukocyte infiltration, neuronal death, and inflammatory mediators, including IL-1 $\alpha$, inducible NO synthase, and TNF- $\alpha$. This highlights that pathophysiological exacerbation depends not only on lymphocytes and monocytes, but also on inflammatory mediators and the action of astrocytes (89). In addition, the selective elimination of microglia results in significantly augmented infarct volume after ischemic insult, indicating the positive function of microglia (90). Moreover, minocycline treatment diminishes polymorphonuclear cells and inhibits microglial activation, which results in the attenuation of neuroinflammation in the ischemic injured brain (91). Furthermore, microglial depletion induced by liposome-encapsulated clodronate was shown to accelerate inflammation and brain injury by a surge of pro-inflammatory cytokines (e.g., IL-1 $\beta$ and TNF- $\alpha$ ) and chemokines (e.g., MCP-1 and MIP-1 $\alpha$ ) in an acute postnatal (day 7) ischemic model (92). This, in turn, indicates that microglial contribution is a critical endogenous defense mechanism in ischemic stroke.

On the other hand, the deleterious role of activated microglia has also been reported. For example, microglia are more prone to releasing cytotoxic factors, such as ROS, NO, and TNF- $\alpha$, in a severe ischemic environment compared to a mild ischemic environment (93). Furthermore, the preconditioning of isoflurane inhibits microglial activation, thereby reducing the infarct volume and attenuating neuronal apoptosis, supporting the detrimental role of microglia in neuroinflammation after ischemic stroke (94).

The copious amount of studies reporting controversial theories regarding the role of microglia in ischemic stroke reflects the importance of microglia and indicates the potential of exploring new therapeutic strategies related to microglia.

\section{Monocyte-Derived Macrophages}

The process of monocytes homing in on inflamed tissue after ischemic stroke is a vital response for host defense. Before monocyte and leukocyte recruitment occurs at the injury site, cytokine and chemokine levels increase, contributing to ischemic stroke outcomes (95). After the onset of ischemic stroke, monocytes circulating in the blood infiltrate into the brain lesion through the disrupted blood-brain barrier (BBB) following the leukocyte cascade as a result of neuroinflammation (9699). Monocyte infiltration is induced by several chemokines. Many researchers have focused their studies on MCP-1, which is also known as chemokine [C-C motif] ligand (CCL2) $(100,101)$. CCL2 is a potent chemokine-specific recruiter for monocytes, and its receptor, CCR2, is required for the egress of classical monocytes to the bloodstream from the BM. An increased level of circulating MCP-1 is associated with increasing the long-term risk of ischemic stroke (102), and the infiltration of CCR2 ${ }^{+}$monocytes is greatly diminished in mice with dysfunctional CX3CR1-CCR2 signaling, resulting in the attenuation of acute injury in a rodent model of childhood stroke (61). CCR2 is highly associated with the recruitment of pro-inflammatory monocytes to the ischemic brain (103). However, Yang et al. showed that remote ischemic limb conditioning (RLC) after ischemic stroke shifted peripheral blood monocytes to the $\mathrm{CCR} 2^{+}$pro-inflammatory monocytes subset, resulting in reduced acute brain infarct volume and brain swelling and improved functional recovery (104). The authors demonstrated that RLC-mediated protection against ischemic stroke injury is disrupted by the adoptive transfer of CCR2-deficient monocytes, highlighting the importance of the RLC-induced shift of monocytes into the CCR2 ${ }^{+}$ monocyte subset in attenuating ischemic stroke outcomes. Recent studies have reported that long-term behavioral recovery was exacerbated by blocking monocyte recruitment following ischemic stroke in mice. To summarize, the number of monocytes recruited to the ischemic hemisphere peaks 3 days after stroke. Half of these infiltrating monocytes differentiate 
TABLE 1 | miRNAs-related monocyte heterogeneity.

\begin{tabular}{|c|c|c|c|c|}
\hline \multicolumn{2}{|l|}{ Monocyte functions } & Pro-inflammatory & Anti-inflammatory & Anti-inflammatory \\
\hline \multicolumn{5}{|c|}{ 1. Heterogeneity of monocyte subsets related with miRNA expression in basal condition } \\
\hline \multirow[t]{2}{*}{ Monocyte phenotype } & Human & CD14 $4^{++}$CD16 $6^{-}$ & $\mathrm{CD} 14^{+} \mathrm{CD} 16^{+}$ & $\mathrm{CD} 14^{+} \mathrm{CD} 16^{++}$ \\
\hline & Mouse & 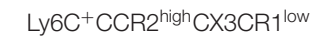 & - & Ly6C $^{-} \mathrm{CCR} 2^{\text {low }} \mathrm{CX} 3 \mathrm{CR} 1^{\text {high }}$ \\
\hline Expression level of miRNAs & $\begin{array}{l}\text { miRNA-17 } \\
\text { miRNA-18a/b } \\
\text { miRNA-19b } \\
\text { miRNA-20b } \\
\text { miRNA-106a } \\
\text { miRNA-432 } \\
\text { miRNA-150 } \\
\text { miRNA-132 } \\
\text { miRNA-146a } \\
\text { miRNA-342-3p } \\
\text { miRNA-19a } \\
\text { miRNA-21 }\end{array}$ & $\begin{array}{l}\text { High } \\
\text { High } \\
\text { High } \\
\text { High } \\
\text { High } \\
\text { Low } \\
\text { High } \\
\text { Low } \\
\text { Low } \\
\text { Low } \\
\text { Low } \\
\text { Low }\end{array}$ & $\begin{array}{l}\text { BLow } \\
\text { Moderate } \\
\text { Moderate } \\
\text { Low } \\
\text { Low } \\
\text { Moderate } \\
\text { Low } \\
\text { Moderate } \\
\text { Moderate } \\
\text { Moderate } \\
\text { Moderate } \\
\text { Moderate }\end{array}$ & $\begin{array}{l}\text { Low } \\
\text { Low } \\
\text { Low } \\
\text { Low } \\
\text { Low } \\
\text { High } \\
\text { High } \\
\text { High } \\
\text { High } \\
\text { High } \\
\text { High } \\
\text { High }\end{array}$ \\
\hline \multicolumn{5}{|c|}{ 2. Implications related to the role of miRNAs in monocyte subsets } \\
\hline miRNA-21 deletion & \multicolumn{4}{|c|}{ Increase of pro-inflammatory response } \\
\hline miRNA-19a knockdown & \multicolumn{4}{|c|}{ Inhibition of $\mathrm{CD}_{16}^{-}$monocytes movement } \\
\hline \multirow[t]{2}{*}{ miRNA-146a deletion } & \multicolumn{4}{|c|}{ Dysregulation of myeloproliferation and myelodifferentiation of HSCs } \\
\hline & \multicolumn{4}{|c|}{ Dysregulation of pro-inflammatory response } \\
\hline \multicolumn{2}{|l|}{ miRNA-150 deletion } & \multicolumn{3}{|c|}{ Decrease of Ly6C $\mathrm{C}^{-}$monocyte by overexpression of Tet3 gene } \\
\hline \multicolumn{2}{|l|}{ miRNA-432 overexpression } & \multicolumn{2}{|c|}{ Increase of $\mathrm{CD} 16^{-}$monocyte apoptosis } & \\
\hline
\end{tabular}

into pro-inflammatory macrophages (M1), whereas the other half exhibit an anti-inflammatory macrophage (M2) phenotype. However, treatment with CCR2 antibody, MC-21, drastically decreases the expression of anti-inflammatory genes, resulting in the abolishment of long-term behavioral recovery (105). In the same context, monocyte/macrophage deletion increases the $\mathrm{M} 1 / \mathrm{M} 2$ polarization ratio of microglia, aggravating the ischemic stroke injury. These results indicate that infiltrating monocytederived macrophages may regulate microglial polarization by shifting excessive pro-inflammatory M1 polarization to the M2 restorative process of microglia (106).

It has been generalized that once resident microglia and infiltrating monocytes turn into macrophages in response to ischemic injury, it is hard to differentiate the origins of the macrophages, as they are morphologically similar (107). To overcome this matter, Tanaka et al. conducted a series of experiments in tracing monocytes/macrophages derived from BM. Chimeric mice expressed enhanced green fluorescent protein in a cerebral ischemic environment, revealing differences in the exact roles of resident microglia and monocyte-derived macrophages (108).

Meanwhile, in addition to the CCR2-CCL2 axis, another chemokine axis pertaining to monocytes in ischemic stroke has been reported. C-C motif ligand 5 (CCL5) inhibition induced by the addition of MKEY, an antagonist of CXCL4-CCL5 heterodimer formation, was shown to significantly reduce the infiltration of $\mathrm{Ly} 6 \mathrm{C}^{+}$monocytes, resulting in the attenuation of classical monocyte-mediated neuroinflammation in a model of experimental ischemic stroke (109). Moreover, repetitive hypoxic preconditioning prior to the onset of ischemic stroke, which induces upregulated CXCL12 levels, blocks leukocyte infiltration, thereby endogenously contributing to an anti-inflammatory phenotype (110). In contrast to $\mathrm{Ly} 6 \mathrm{C}^{+}$monocytes, $\mathrm{Ly}^{+} \mathrm{C}^{-}$ alternative monocytes have a different path of infiltration. CX3CR1 ligand fractalkine (CX3CL1), which is expressed in endothelial and neuronal cells (111), interacts with $\mathrm{Ly}_{6} \mathrm{C}^{-}$ monocytes that are patrolling the vasculature (112) and microglia that are surveilling the CNS environment. Both Ly6C $\mathrm{C}^{-}$monocytes and microglia highly express its receptor, CX3CR1 (113), under physiological conditions. At the onset of ischemic stroke, these interactions are disrupted, and as the level of CX3CL1 abnormally increases, Ly6C ${ }^{-}$monocytes rapidly infiltrate the brain parenchyma (114), leading to microglial activation. The regulation of transforming growth factor $\beta$ activated kinase 1 (TAK1), which is involved in both innate and adaptive immune responses and has conflicting inflammatory effects depending on the cell type, plays a key role in monocyte infiltration into the injury site following ischemic stroke. TAK1 deletion leads to reduced monocyte infiltration, thereby improving outcomes after ischemic stroke (115). In addition, Werner et al. demonstrated that CXC motif chemokine receptor 4 (CXCR4) deficiency diminishes monocyte infiltration and dampens the levels of pattern recognition and defense response gene expression in monocyte-derived macrophages at the ischemic injury site, resulting in deteriorated ischemic stroke outcomes. These results indicate that CXCR4 distinguishing HSC-derived monocytes from microglia is a crucial factor in sustaining the beneficial role of monocytes through an innate immune system against neuroinflammation following ischemic stroke (116). 


\section{CONVERSION OF MONOCYTES AFTER ISCHEMIC STROKE}

There has recently been a surge in interest regarding the origin

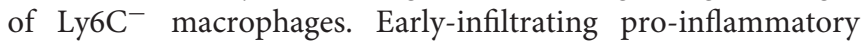
monocytes can differentiate into anti-inflammatory $\mathrm{Ly}^{-} \mathrm{C}^{-}$ wound macrophages (MONO to MØ) after ischemic stroke (117). In addition, CCR $2^{\text {high }} \mathrm{CX} 3 \mathrm{CR} 1^{\text {low }}$ pro-inflammatory monocytes have been shown to turn into CCR $2{ }^{\text {low }} \mathrm{CX} 3 \mathrm{CR} 1^{\text {high }}$ anti-inflammatory macrophages (MONO to MØ) 3 days after ischemic stroke in $\mathrm{CX} 3 \mathrm{CR} 1^{\mathrm{gfp} /+-} \mathrm{CCR} 2^{\mathrm{rfp} /+}$ functional transgenic mice using two-photon intravital imaging, indicating that monocytes play a notable role in neuroinflammation following ischemic stroke (118).

Recently, the originally proposed dogma has been challenged in regard to the role of monocytes and monocytes differentiating into macrophages in the immune response. Jakubzick et al. revealed through parabiosis and bromodeoxyuridine pulse-chase analysis that monocytes can enter tissues and transmigrate to lymph nodes, maintaining their markers as monocytes, while not expressing macrophage or dendritic cell (DC) markers. In other words, classical monocytes are able to minimally differentiate into macrophages or DCs, surveying the nonlymphoid tissue and transporting antigens to lymph nodes under a steady state (119). However, this new concept of monocytes (MONO to MONO) has not been observed in the ischemic stroke environment (Figure 2). Future studies are warranted to examine whether the MONO-to-MONO conversion occurs after ischemic stroke.

\section{MONOCYTE BIOMARKERS IN CLINICAL STUDIES OF ISCHEMIC STROKE}

Abundant data have been accumulated regarding the overall pathologies of ischemic stroke. Based on these data, novel therapies, such as tissue plasminogen activator (tPA), are used to treat ischemic stroke. However, because several factors, such as sex, age, duration of ischemia, localization of the infarction, and possible comorbidities, must be evaluated for accurate ischemic stroke diagnosis, the treatments available today, such as thrombolytic agents, may only be effective for a narrow range of patients. Moreover, ischemic stroke is not a single neurodisease that leads to a local immune response; rather, it is a systemic inflammatory response that involves immune cells in the blood, making it more complicated to treat. To untangle and understand the complex systemic inflammatory response that follows ischemic stroke, monocytes are a popular research topic in the vast field of stroke. Today, the standard treatment for acute ischemic stroke (AIS) is thrombolytic therapy, which breaks down blood clots to restore blood flow in the brain (120). However, there are limitations to this treatment method, as it is only effective when the treatment is received within 3 to $4.5 \mathrm{~h}$ of symptom onset (121). As there is a narrow time frame for this therapeutic method, many patients are left with no alternative option. Therefore, much effort has been devoted to research new therapeutic methods to prevent the unfortunate outcomes of stroke $(122,123)$. To discover novel methods of ischemic stroke therapy, factors related to inflammation in the brain, such as C-reactive protein (CRP) (124), hepatocyte growth factor (125), insulin-like growth factor-1 (IGF-1), IGF-binding protein-3 (126), factor XIII (127), brain-derived neurotrophic factor (128), and D-dimer (129), have been investigated.

In addition, research on newly identified prognostic biomarkers related to monocytes in AIS has gained interest. Recently, Liu et al. reported that a higher monocyte-to-highdensity lipoprotein ratio (MHR) is highly associated with the risk of poor functional outcomes within 3 months in patients with AIS, thereby suggesting MHR as a novel marker to evaluate ischemic stroke prognosis, widening the treatment window from mere hours to months (130). Wang et al. demonstrated the correlation between macrophage migration inhibitory factor (MIF) serum levels and ischemic stroke, stating that high MIF levels are directly related to moderate or severe ischemic stroke outcomes (131). Another emerging prognostic biomarker for AIS is the lymphocyte-to-monocyte ratio (LMR) (132). In a clinical study, Ren et al. assessed the stroke severity of 512 patients with AIS and 3 month outcomes using the National Institute of Health Stroke Scale (NIHSS) and conducted a series of experiments to evaluate relevant AIS markers, showing that a lower LMR is closely associated with severe AIS and poor outcomes. Similarly, a lower LMR is independently related to higher risk of hemorrhagic transformation (HT) in patients with AIS (133), suggesting that the LMR upon admission has good predictive value for AIS prognosis and may be used as a predictor for HT.

It has also been reported that T-cell immunoglobulin and mucin domain (TIM-4) expression levels in monocytes are remarkably elevated in patients with AIS after 2 and 5 days when compared to control patients. Importantly, TIM-4 expression levels in non-classical monocytes are highly correlated with NIHSS scores 2 days after stroke and are significantly increased in patients with AIS and poor outcomes, suggesting that the percentage of TIM-4 expression in non-classical monocytes could be a biomarker in predicting the clinical course and prognosis in AIS (134) (Table 2). In summary, numerous studies on biomarkers for the detection of ischemic stroke have been actively conducted in clinical practice; however, more work is needed to identify monocytes as a novel predictor of ischemic stroke. Therefore, research to discover biomarkers related to monocytes should be continued as it may lead to more promising stroke prognoses.

\section{TRANSCRIPTOME PROFILING OF MONOCYTE/MACROPHAGE IN ISCHEMIC STROKE: A PROMISING GENE-TARGETING THERAPY?}

At present, there is no effective therapy against ischemic stroke and its sequelae. A variety of proteins have been studied (135) to confirm accurate ischemic stroke diagnosis and mitigate the neuroinflammation following ischemic 

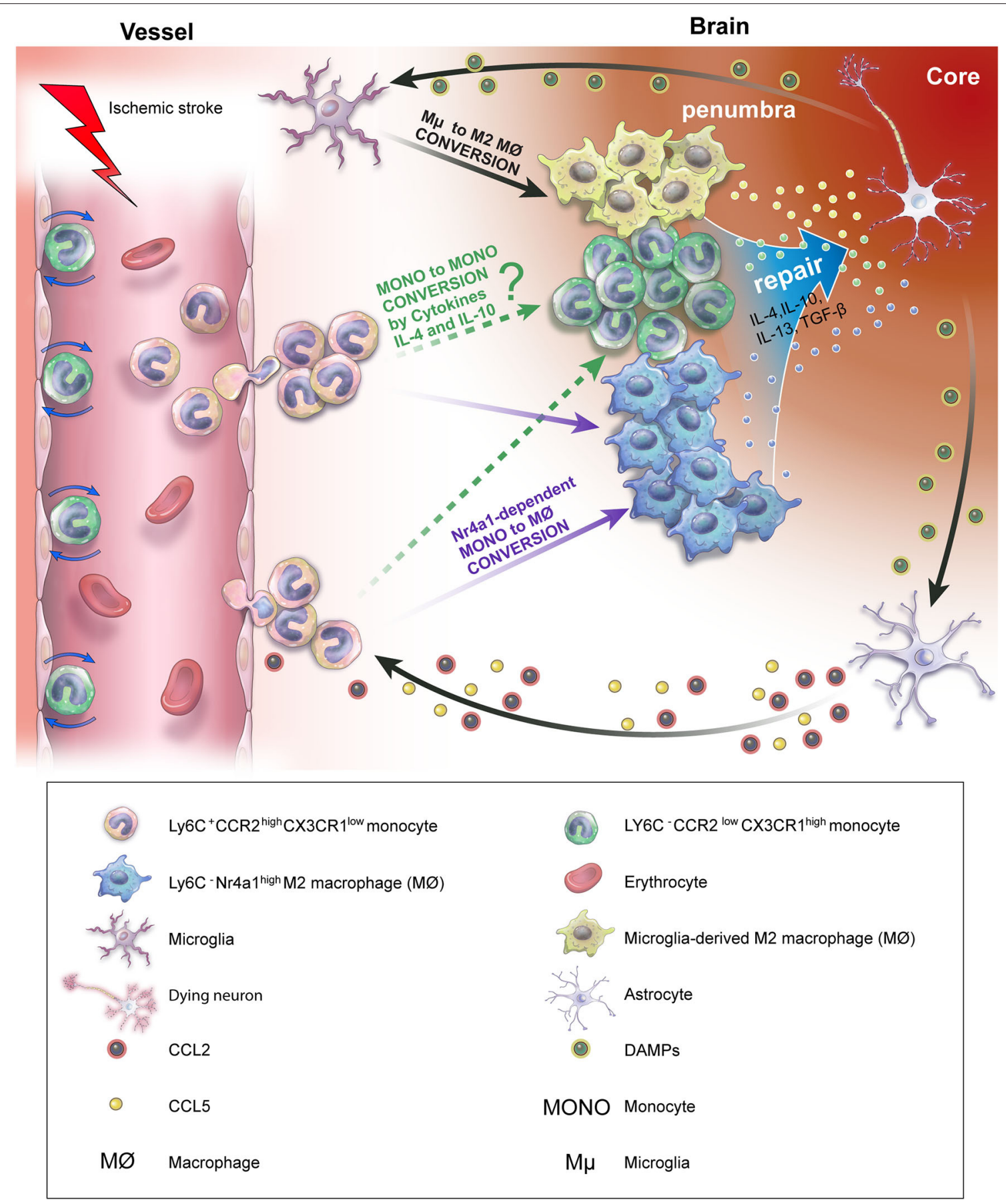

FIGURE 2 | Ly6C+ pro-inflammatory monocyte conversion and contribution to ischemic stroke recovery in vivo. After the onset of ischemic stroke, DAMP released by dying neurons activates microglia and astrocytes. C-C motif ligand 2 (CCL2) and C-C motif ligand 5 (CCL5), which are secreted by activated microglia and astrocytes, induce the infiltration of $\mathrm{Ly}_{6 \mathrm{C}}{ }^{+}$pro-inflammatory monocytes into the injury site. Infiltrating $\mathrm{Ly}_{6 \mathrm{C}}{ }^{+}$monocytes convert into $\mathrm{M} 2$ macrophages depending on the presence of $\mathrm{Nr} 4 a 1$ (MONO to $\mathrm{MØ).} \mathrm{In} \mathrm{addition,} \mathrm{activated} \mathrm{microglia} \mathrm{are} \mathrm{polarized} \mathrm{into} \mathrm{M2} \mathrm{macrophages,} \mathrm{releasing} \mathrm{anti-inflammatory} \mathrm{cytokines,} \mathrm{resulting} \mathrm{in} \mathrm{ischemic}$ stroke recovery. However, whether the conversion of Ly6C+ pro-inflammatory monocytes to Ly6C- anti-inflammatory monocytes (MONO to MONO) occurs in the brain, attenuating neuroinflammation following ischemic stroke, remains unclear.

stroke. Despite these efforts, successful therapeutics that are applicable to clinical studies regarding ischemic stroke have not been investigated.
Studies have recently been conducted in the field of stroke regarding the use of RNA in peripheral blood (136). These studies are supported by clinical applications in the diagnosis of diseases, 
TABLE 2 | Monocyte-related biomarkers of acute ischemic stroke (AIS) outcomes.

\begin{tabular}{|c|c|c|c|c|}
\hline Biomarkers & Biomarker levels indicating severe AIS & ${ }^{\star} \mathrm{OR} /{ }^{* \star}(r)$ & $P$-value & References \\
\hline $\mathrm{MHR}$ & High & $2.58^{*}$ & 0.015 & $(130)$ \\
\hline MIF & High & $1.06^{*}$ & $<0.01$ & $(131)$ \\
\hline LMR & Low & $0.523^{\star}$ & 0.029 & $(133)$ \\
\hline TIM-4 & High & $0.351^{\star \star}$ & 0.048 & $(134)$ \\
\hline
\end{tabular}

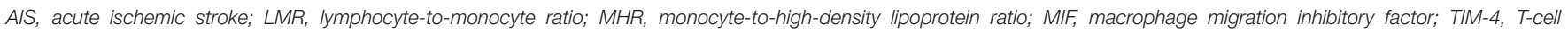
immunoglobulin and mucin domain-4. " OR, odds ratio; ${ }^{\star \star} r$, correlative coefficient.

such as myocardial infarction (137) and cancer (138). Brain transcriptomic analysis has been used in many experimental ischemic stroke studies to investigate specific changes in gene expression. These studies were mostly conducted in rodent models of ischemic stroke (139). As simultaneous blood and brain transcriptomics in patients with ischemic stroke is not feasible, Ramsay et al. conducted a series of experiments to analyze the whole gene expression pattern in both the blood and brain after ischemic stroke in a primate stroke model using Rhesus macaque (140).

Monocytes and macrophages infiltrate the ischemic injured brain and significantly impact ischemic stroke outcomes by regulating neuroinflammation. Hence, to investigate the exact role of monocytes and macrophages after ischemic stroke, current research trends have focused on transcriptome profiling (141).

Recently, Wang et al. performed genome-wide transcriptome profiling using RNA sequencing (RNA-seq) of monocytes and macrophages in the blood and brain samples of an ischemic stroke rodent model with distal middle cerebral artery occlusion (dMCAO) (142). Their findings indicated that ischemic stroke induced significant transcriptome changes in monocytes and macrophages in the post-stroke brain; however, only moderate changes were observed in the blood samples of the ischemic stroke group when compared with the control group. Further, macrophages in the post-ischemic stroke brain display unique transcriptome characteristics, robustly favoring neurovascular plasticity 5 days after ischemic stroke, suggesting that macrophages in the brain upregulate genes related with neovascularization, such as oncostatin $\mathrm{M}(\mathrm{Osm})$ (143), osteopontin (Spp1) (144), growth differentiation factor 15 (GDF15) (145), vascular endothelial growth factor (VEGF) (146), and fibroblast growth factor 1 (FGF1) (147). Surprisingly, lower angiogenesis and neurogenesis were verified in myeloid cellspecific peroxisome proliferator-activated receptor $\gamma(\operatorname{PPAR} \gamma)$ knockout $(\mathrm{mKO})$ mice than in wild-type mice 5 days after ischemic stroke. These results suggest that $\operatorname{PPAR} \gamma$, a master regulator of monocyte/macrophage genomic reprogramming, is a novel therapeutic target in determining reparative macrophage phenotypes and improving neurological function following ischemic stroke (142).

Another study by Zhang et al. revealed that PPAR $\gamma$ and signal transducer and activator of transcription 6 (STAT6) are potential upstream regulators of efferocytosis-related genes in macrophages, driving pro-efferocytic and anti-inflammatory phenotypes in the brain, thereby promoting ischemic stroke injury and recovery (148). To summarize, the blood-borne infiltrating monocyte/macrophage population, which is phenotypically expressed as CD11c-Ly6G ${ }^{-} \mathrm{CD} 11 b^{+} \mathrm{CD} 45^{\text {high }}$ sorted by FACS in the brain, upregulates genes related with phagocytic activities, such as triggering receptor expressed on myeloid cells-1 (TREM1) (149) and extracellular signalregulated kinase 5 (ERK5) (150), 5 days after dMCAO. In addition, genes involved in recruiting phagocytes, such as those encoding purinergic receptor 2 (P2Y2) and S1P receptor (S1PR1), were remarkably upregulated in brain monocytes/macrophages when compared with blood monocytes 5 days after dMCAO. Additionally, genes participating in the engulfment of apoptotic cells, such as Abcal, Prkaca, and Rac1, and representative cytoskeletal regulators (Phldb2, Stmn1, Cit, Rac1, Cttn, Aurka, and Baiap2) were significantly upregulated in brain macrophages compared with blood monocytes, suggesting that active engulfment signaling and cytoskeletal rearrangement in brain macrophages occur 5 days after dMCAO. Importantly, according to upstream regulator analysis, PPAR $\gamma$ and STAT6 may play pivotal roles in determining the pro-efferocytic transcriptome of macrophages in the brain 5 days after ischemic stroke (148). Regarding the transcriptome profiling, although the results could expand our knowledge of the exact role of monocytes and macrophages in the cerebral ischemic environment, the findings do not generalize all cases of ischemic stroke, as the results were only obtained from a single time point 5 days after ischemic stroke. Therefore, future studies may be warranted to confirm and examine the temporal profile of monocyte/macrophage genomic changes.

\section{ANTI-INFLAMMATORY DRUGS RELATED TO MONOCYTES AND MACROPHAGES FOR TREATMENT OF ISCHEMIC STROKE}

Until recently, inflammatory monocytes recruited to the brain were believed to be representative mediators of neuroinflammatory injury and secondary neurotoxicity after ischemic stroke. Therefore, therapeutic intervention targeting CCR2 to prevent the recruitment of pro-inflammatory monocytes was considered to be beneficial against ischemic stroke, even though available data were controversial regarding monocytes roles after ischemic stroke $(151,152)$. These controversial aspects of monocytes were totally dependent on 
the severity and time window of the ischemic stroke, which suggested the importance of new therapeutics that could modulate the activity of monocytes in ischemic stroke. Current ischemic stroke treatments are focused on anti-inflammatory strategies that convert the complex characteristics of monocytes into anti-inflammatory proprieties following ischemic stroke.

Aspirin is a non-selective cyclooxygenase inhibitor that can prevent macrophage accumulation, resulting in cerebrovascular protection in the model of stroke-prone spontaneously hypertensive rats (SHRSP) (153). It has also been reported that aspirin delays the onset of ischemic stroke (153), providing clinical proofs of its protective effect against stroke in humans (154). Further, rosuvastatin, a widely used statin for lowering cholesterol and high-sensitivity CRP $(155,156)$, showed to attenuate the transcription of inflammatory biomarkers, such as MCP-1, IL- $1 \beta$, TNF- $\alpha$, TGF- $\beta 1$, and p-selectin, while increasing the mRNA of endothelial NO synthase, overall supporting the anti-inflammatory processes in stroke-prone rats (157). Although it was reported that the use of statins is associated with augmented occurrences of hemorrhagic stroke in patients with a clinical history of cerebrovascular disease, they can be beneficial in preventing ischemic stroke (158). In the preclinical systematic review conducted by White et al., the PPAR $\gamma$ agonists thiazolidinediones, including rosiglitazone and pioglitazone, were found to suppress the cyclooxygenase- 2 expression and promote the PPAR $\gamma$ DNA binding, resulting in the inhibition of inflammation after ischemic stroke (159). In addition, Nakamura et al. demonstrated that pioglitazone inhibits the infiltration of macrophages and suppresses the expression of inflammatory cytokines such as MCP-1 and TNF- $\alpha$, thereby exerting a neuroprotective effect in SHRSP (160). Another anti-inflammatory drug targeting microglia and macrophages is minocycline, a known semisynthetic tetracycline antibiotic with antiapoptotic properties. It was demonstrated that minocycline inhibits activated microglia/macrophages that are involved in the demise of neurons and astrocytes, as well as endothelial cells in neurological diseases $(161,162)$. Evidence supporting the anti-inflammatory effect of minocycline showed that early treatment with this drug reduces the number of activated microglia/macrophage in the peri-infarct lesion of the ischemic injured brain, resulting in improved neurological outcomes after ischemic stroke in rats (163) (Table 3).

From the strategies of ischemic stroke treatment currently available, the best therapeutic approach in the acute phase is thrombolysis with tPA; however, the therapeutic time window is extremely narrow ( $<4.5 \mathrm{~h}$ within stroke onset) (164). To expand the therapeutic window and, consequently, reach more patients with ischemic stroke, recent studies have focused on investigating immune cell-targeted therapies, such as anti-inflammatory drugs that are fundamentally non-invasive and effective approaches for ischemic stroke prevention (165). Despite substantial efforts to find an effective treatment for ischemic stroke through pharmacological modulation of immune cells, this still remains a challenge. As inflammatory mechanisms following ischemic stroke are complex, with multiple deleterious and protective effects, recent clinical trials of immunological therapies have failed (166-168). Importantly, most in vitro and in vivo studies regarding ischemic stroke were performed at the level of a single disease, not including comorbidities, such as hyperglycemia or diabetes. It was reported that most patients with stroke have comorbidities (169). Therefore, future studies should address ischemic stroke using models that mimic the disease, as well as its comorbidities, similar to patients, in order to develop more specific and accurate therapeutics.

As outlined above, recent emerging targets of monocytes transmodulation for ischemic stroke treatment have been focused on two factors, Nr4a1 and PPAR $\gamma(170,171)$. As a vital factor for survival of non-classical monocytes, $\mathrm{Nr} 4 \mathrm{a} 1$ plays an important role in the differentiation of $\mathrm{Ly}^{+} \mathrm{C}^{+}$monocytes toward the anti-inflammatory phenotype of M2 macrophages, which has been proven in defective myocardial remodeling studies using Nr4a1 ${ }^{-/}$mice (172). Furthermore, monocytes/macrophages polarization against neuroinflammation via pharmacological PPAR $\gamma$ activation in hyperglycemic and PPAR $\gamma(\mathrm{KO})$ mice resulted in brain repair with neovascularization in the infarct border zone after ischemic stroke. These findings suggest that Nr4al and PPAR $\gamma$ are strong modulators of $\mathrm{Ly}^{+} \mathrm{C}^{+}$ monocytes toward anti-inflammatory macrophage polarization, without affecting the infiltration of monocytes into the injured brain tissue.

Past studies have intensively researched whether the infiltration of CCR2 ${ }^{+}$inflammatory monocyte or inhibition of CCR2 expression on monocytes affects post-ischemic stroke. Moreover, the role of inflammatory monocytes is known to vary in a time-dependent manner. Therefore, future therapeutic strategies may need to focus on increasing the polarization of infiltrating monocytes into macrophages with anti-inflammatory properties (M2) through modulation of factors such as Nr4a1, PPAR $\gamma$, and miRNAs (e.g., miRNA-21, miRNA-146a) (Figure 3).

\section{BIOTECHNOLOGIES FOR TREATMENT OF ISCHEMIC STROKE: CURRENT ADVANCEMENTS AND FUTURE DIRECTIONS}

Numerous studies in preclinical and clinical trials aim to discover functional recovery after ischemic stroke. From this point of view, immunoregulation by pharmacological drugs and neurogenesis stimulation, such as stem cell transplantation, have been considered as pivotal mechanisms in ischemic stroke treatment. However, despite these tremendous efforts to overcome ischemic stroke, no clear approaches for ischemic stroke therapy have been validated until now. With the recent advancements in science, various research regarding treatments of ischemic stroke using various cutting-edge technologies have been reported (Figure 4).

\section{CRISPR/Cas9 System}

Clustered regularly interspaced short palindromic repeats (CRISPR)/Cas9 genome editing has emerged as a powerful tool that enables the correction of DNA mutation in both in vitro and in vivo models. CRISPR/Cas9 system is also known to be effective in creating gene $\mathrm{KO}$ and knock-in animal 
TABLE 3 | Current ischemic stroke therapeutics targeting anti-inflammation.

\begin{tabular}{|c|c|c|}
\hline Therapeutics & Role(s) & Effect(s) on stroke \\
\hline Aspirin & - Non-selective cyclooxygenase inhibitor & $\begin{array}{l}\text { - Decrease the accumulation of macrophages } \\
\text { - Delays the onset of ischemic stroke }\end{array}$ \\
\hline Rosuvastatin & $\begin{array}{l}\text { - Lowers low-density lipoprotein cholesterol } \\
\text { - Lowers high-sensitivity CRP levels }\end{array}$ & $\begin{array}{l}\text { - Attenuate the expression of inflammatory } \\
\text { biomarkers: MCP- } 1, \mathrm{IL}-1 \beta \\
\text { TNF- } \alpha \text {, TGF- } \beta 1, \mathrm{p} \text {-selectin }\end{array}$ \\
\hline Thiazolidinediones & - PPAR $\gamma$ agonists & $\begin{array}{l}\text { - Suppress the cyclooxygenase-2 expression } \\
\text { - Inhibit the infiltration of macrophages } \\
\text { - Decrease the expression level of MCP-1 and TNF- } \alpha \\
\text { - Promote the PPAR } \gamma \text { DNA binding }\end{array}$ \\
\hline Minocycline & - Semisynthetic tetracycline antibiotic & $\begin{array}{l}\text { - Reduce the microglia/macrophage activation } \\
\text { - Improves the neurological outcome }\end{array}$ \\
\hline
\end{tabular}

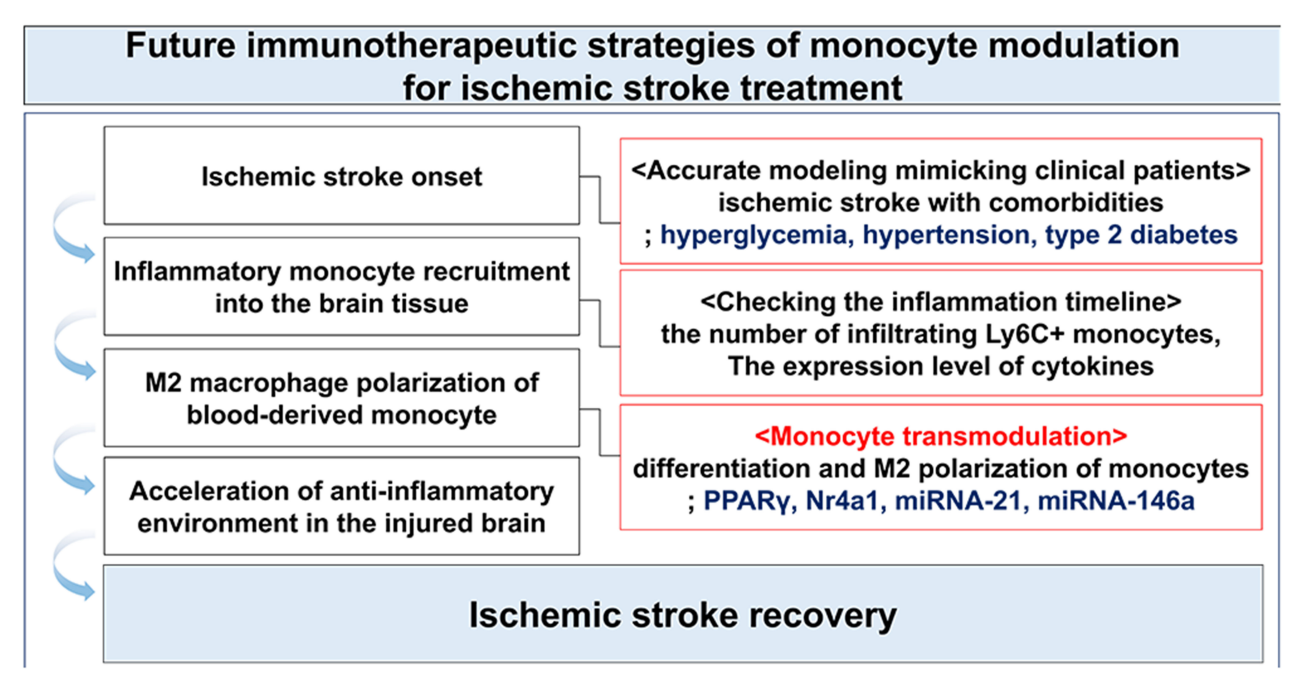

FIGURE 3 | Immunotherapeutic strategy through the modulation of monocytes following ischemic stroke.

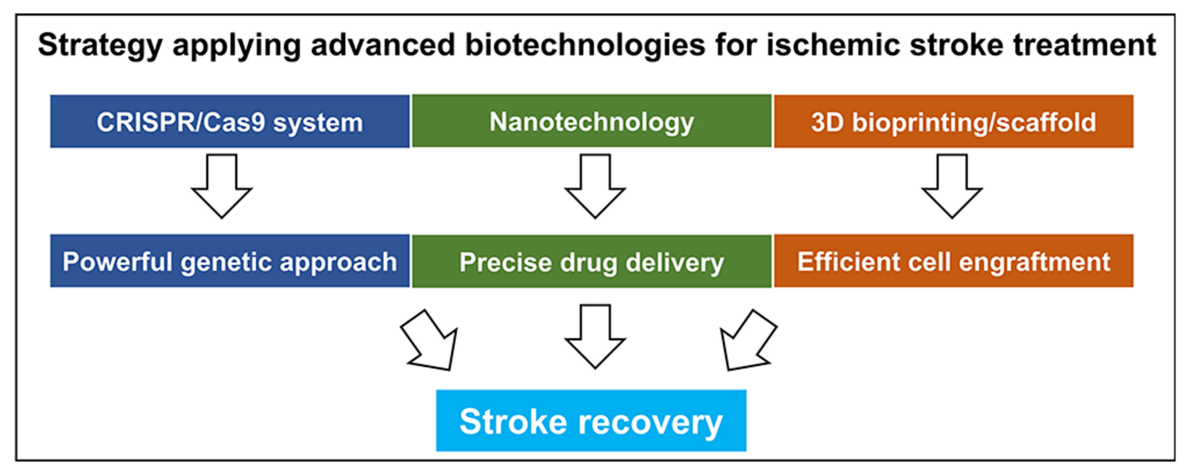

FIGURE 4 | Current advanced biotechnologies for treatment of ischemic stroke.

models for investigating the biological and pathophysiological mechanisms in various diseases (173). Recently, studies applying the advantages of CRISPR/Cas9 system have been reported in the field of stroke. It has been reported that the inhibition of semaphorin 4D (Sema4D), an axon guidance molecule, and its receptor, PlexinB1, which has the highest affinity to Sema4D, remarkably attenuate the inflammatory responses and $\mathrm{BBB}$ permeability and significantly reduce the infarct volume, resulting in the improvement of ischemic stroke outcome. The researchers in the study provided decisive evidence demonstrating the effect of Sema4D/PlexinB1 signaling using lentiviral transfection system targeting PlexinB1 disruption 
through CRISPR gene editing, which suggests that the regulation of Sema4D/PlexinB1 signaling is a novel therapeutic target for acute-phase treatment of ischemic stroke (174). Another study using CRISPR/Cas9 system in a genetic approach has been reported. Li et al. demonstrated that neuronal apoptosis was highly protected through Akt activation in ischemia-reperfusion (I/R) injury in Tollip-deficient rats, suggesting that Tollip is a novel modulator of $\mathrm{I} / \mathrm{R}$ injury by promoting neuronal apoptosis and neuroinflammation (175). So far, despite the numerous advancements made through various genetic manipulations regarding the potential treatments of ischemic stroke, treatments targeting monocyte transmodulation using CRISPR/Cas9 system have not yet been reported. Therefore, future research to overcome this matter would be needed to continue as it may lead to more promising ischemic stroke treatment.

\section{Applied Nanotechnologies}

As ischemic stroke occurs through different etiologies and pathophysiologies, the evolution of damage is complex and dynamic. Technologies based on structural and molecular brain imaging and effective drug delivery are necessary to apply precise and appropriate treatments at different phases. As a result, nanotechnologies, which involve nanomaterials, such as liposomes, nanocapsules, nanotubes, and micelles, have been developed for the treatment of stroke (176). Furthermore, to accurately assess a prognosis and overcome the difficulties limiting the present treatment of ischemic stroke, efforts to develop new biomarkers and investigate factors related to monocytes following ischemic stroke are ongoing in clinical studies. Recently, new assessments have been applied in clinical studies to improve the outcomes of ischemic stroke. Hou et al. reported the results of a new trial that showed that using monocytes and neutrophils, which were developed as carriers for cRGD [cyclo (Arg-Gly-Asp-D-Tyr-Lys)] liposomemediated drug delivery, may alleviate ischemic stroke outcomes (177). Targeting monocyte that protects neuronal cell death through nanotechnology could be a novel therapeutic strategy for ischemic stroke. However, few optimal "nano" -related studies regarding immunomodulation of monocytes in ischemic stroke have been reported yet. Future studies are warranted to resolve the complexity of ischemic stroke in the context of nanotherapy targeting monocytes.

\section{Three-Dimensional Bioprinting}

The main goal of ischemic stroke treatment is to promote the neurogenesis and angiogenesis, thereby improving the functional outcomes. However, few patients with ischemic stroke onset can be served timely with thrombolytic treatment, which mainly focuses on the rapid reperfusion, from the acute phase of occlusion. Therefore, to overcome the limitations, strategies ultimately promoting neurorecovery have been investigated (178). As a part of these therapeutic strategies, bioprinting, an emerging modern technology mixing cells related with tissue regeneration, such as stem cells, with biomaterials that are designed with high precision in order to obtain high compatibility with host tissues, has been developed $(179,180)$. Recently, it was reported that implanted exogenous human neural progenitor cells, which are electrically preconditioned on a conductive biopolymer scaffold prior to transplantation, cause the endogenous vasculature changes that enhance the gene expression involved in VEGF-A pathway, resulting in improvement of functional recovery after ischemic stroke (181). In addition, Brzezinski et al. demonstrated the efficacy of $3 \mathrm{D}$ printed novel holdfast devices. Briefly, left atrial appendage (LAA) occlusion is used as a method of preventing ischemic stroke in patients with atrial fibrillation. LAA exclusion device based on $3 \mathrm{D}$ printing using the selective laser sintering technology with polyamide powder was tested in this research because of its broad accessibility and low costs for production. The researchers tested for the reactions with local tissue and biocompatibility of the device when implanted in swine models. Results showed no clots on the atrium surface, and the foreign body reaction levels were similar to that of a polyester graft. This novel device that was evaluated in the research meets the biocompatibility parameters without any issues; that is, it is a suitable device for stroke prevention (182).

\section{CONCLUSION}

During the past decade, significant progress has been achieved in the understanding and treatment of ischemic stroke. In particular, many studies have investigated the role of monocytes from various angles, including cellular and genetic approaches. The evidence discussed here suggests that the application of transcriptomics and epigenomics targeting monocyte/macrophage plays a crucial role in the regulation of neuroinflammation following ischemic stroke. The advancements in proteomics have remarkably contributed to development of novel biomarkers related to monocytes in evaluating the prognosis of ischemic stroke in clinical studies. The role of infiltrating monocytes in ischemic stroke is still controversial as it varies depending on timing and the degree of damage. This conflicting discussion supports vital evidence related to the importance of monocytes and the potential to convert into beneficial M2 macrophages by transmodulation. Several studies related to $\mathrm{Ly} 6 \mathrm{C}^{-}$alternative monocytes have also been reported in the field of ischemic stroke. Therefore, further research regarding alternative monocytes and the transmodulation of classical monocytes with the application of advanced biotechnologies is necessary, as it may open doors to new therapeutic strategies for stroke. Taken together, immunomodulation that aims to specifically control the functions of each monocyte subset is a curtail strategy for developing new therapies and may provide a promising future for the treatment of ischemic stroke.

\section{AUTHOR CONTRIBUTIONS}

JP and JC equally contributed to this study. This manuscript was written by JP and JC. JL and JK participated in the discussion and revision. The final manuscript was designed and edited by JL. All authors read and approved the final manuscript. 


\section{FUNDING}

JL secured funding for this research, which was supported by grants from the National Research Foundation of Korea and the Ministry of Science, ICT and Future Planning (NRF2016M3C7A1905098).

\section{REFERENCES}

1. Benjamin EJ, Virani SS, Callaway CW, Chamberlain AM, Chang AR, Cheng S, et al. Heart disease and stroke statistics-2018 update: a report from the American Heart Association. Circulation. (2018) 137:e67-492. doi: 10.1161/CIR.0000000000000558

2. Chen AQ, Fang Z, Chen XL, Yang S, Zhou YF, Mao L, et al. Microgliaderived TNF-alpha mediates endothelial necroptosis aggravating blood brain-barrier disruption after ischemic stroke. Cell Death Dis. (2019) 10:487. doi: 10.1038/s41419-019-1716-9

3. Zhang $\mathrm{H}$, Lu M, Zhang X, Kuai $\mathrm{Y}$, Mei $\mathrm{Y}$, Tan Q, et al. Isosteviol sodium protects against ischemic stroke by modulating microglia/macrophage polarization via disruption of GAS5/miR-146a-5p sponge. Sci Rep. (2019) 9:12221. doi: 10.1038/s41598-019-48759-0

4. Meisel C, Schwab JM, Prass K, Meisel A, Dirnagl U. Central nervous system injury-induced immune deficiency syndrome. Nat Rev Neurosci. (2005) 6:775-86. doi: $10.1038 / \mathrm{nrn} 1765$

5. Mena H, Cadavid D, Rushing EJ. Human cerebral infarct: a proposed histopathologic classification based on 137 cases. Acta Neuropathol. (2004) 108:524-30. doi: 10.1007/s00401-004-0918-z

6. Urra X, Cervera A, Villamor N, Planas AM, Chamorro A. Harms and benefits of lymphocyte subpopulations in patients with acute stroke. Neuroscience. (2009) 158:1174-83. doi: 10.1016/j.neuroscience.2008.06.014

7. Okar SV, Topcuoglu MA, Yemisci M, Cakir Aktas C, Oguz KK, Arsava EM. Post-stroke inflammatory response is linked to volume loss in the contralateral hemisphere. J Neuroimmunol. (2020) 344:577247. doi: 10.1016/j.jneuroim.2020.577247

8. Duris $\mathrm{K}$, Jurajda M. Evolutionary concept of inflammatory response and stroke. J Neurosci Res. (2020) 98:98-104. doi: 10.1002/jnr.24392

9. Shen F, Jiang L, Han F, Degos V, Chen S, Su H. Increased inflammatory response in old mice is associated with more severe neuronal injury at the acute stage of ischemic stroke. Aging Dis. (2019) 10:12-22. doi: 10.14336/AD.2018.0205

10. Wood H. Stroke: an alarmin' inflammatory response after stroke. Nat Rev Neurol. (2018) 14:252-3. doi: 10.1038/nrneurol.2018.40

11. Lv W, Xu J, Wang $\mathrm{X}, \mathrm{Li} \mathrm{X}, \mathrm{Xu} \mathrm{Q}$, Xin $\mathrm{H}$. Bioengineered boronic ester modified dextran polymer nanoparticles as reactive oxygen species responsive nanocarrier for ischemic stroke treatment. ACS Nano. (2018) 12:5417-26. doi: 10.1021/acsnano.8b00477

12. Szeto V, Chen NH, Sun HS, Feng ZP. The role of KATP channels in cerebral ischemic stroke and diabetes. Acta Pharmacol Sin. (2018) 39:683-94. doi: $10.1038 /$ aps.2018.10

13. Narne P, Pandey V, Phanithi PB. Role of nitric oxide and hydrogen sulfide in ischemic stroke and the emergent epigenetic underpinnings. Mol Neurobiol. (2019) 56:1749-69. doi: 10.1007/s12035-018-1141-6

14. Fani Maleki A, Rivest S. Innate immune cells: monocytes, monocytederived macrophages and microglia as therapeutic targets for Alzheimer's disease and multiple sclerosis. Front Cell Neurosci. (2019) 13:355. doi: 10.3389/fncel.2019.00355

15. Lai TKY, Zhai D, Su P, Jiang A, Boychuk J, Liu F. The receptor-receptor interaction between mGluR1 receptor and NMDA receptor: a potential therapeutic target for protection against ischemic stroke. FASEB J. (2019) 33:14423-39. doi: 10.1096/fj.201900417R

16. Moskowitz MA, Lo EH, Iadecola C. The science of stroke: mechanisms in search of treatments. Neuron. (2010) 67:181-98. doi: 10.1016/j.neuron.2010.07.002
ACKNOWLEDGMENTS

The authors thank the staff of Medical Illustration \& Design, which is part of the Medical Research Support Services of the Yonsei University College of Medicine, for all the artistic support related to this work. The authors would also like to thank Editage (www.editage.co.kr) for English language editing.

17. Rock KL, Latz E, Ontiveros F, Kono H. The sterile inflammatory response. Annu Rev Immunol. (2010) 28:321-42. doi: 10.1146/annurev-immunol-030409-101311

18. Iadecola C, Anrather J. The immunology of stroke: from mechanisms to translation. Nat Med. (2011) 17:796-808. doi: 10.1038/nm.2399

19. Kim E, Cho S. Microglia and monocyte-derived macrophages in stroke Neurotherapeutics. (2016) 13:702-18. doi: 10.1007/s13311-016-0463-1

20. Marsh BJ, Williams-Karnesky RL, Stenzel-Poore MP. Toll-like receptor signaling in endogenous neuroprotection and stroke. Neuroscience. (2009) 158:1007-20. doi: 10.1016/j.neuroscience.2008.07.067

21. Chtanova T, Schaeffer M, Han SJ, van Dooren GG, Nollmann M, Herzmark $\mathrm{P}$, et al. Dynamics of neutrophil migration in lymph nodes during infection. Immunity. (2008) 29:487-96. doi: 10.1016/j.immuni.2008.07.012

22. McDonald B, Pittman K, Menezes GB, Hirota SA, Slaba I, Waterhouse $\mathrm{CC}$, et al. Intravascular danger signals guide neutrophils to sites of sterile inflammation. Science. (2010) 330:362-6. doi: 10.1126/science.1195491

23. Lammermann T, Afonso PV, Angermann BR, Wang JM, Kastenmuller W, Parent CA, et al. Neutrophil swarms require LTB4 and integrins at sites of cell death in vivo. Nature. (2013) 498:371-5. doi: 10.1038/nature12175

24. Otxoa-de-Amezaga A, Miro-Mur F, Pedragosa J, Gallizioli M, Justicia C, Gaja-Capdevila N, et al. Microglial cell loss after ischemic stroke favors brain neutrophil accumulation. Acta Neuropathol. (2019) 137:321-41. doi: 10.1007/s00401-018-1954-4

25. Perez-de-Puig I, Miro-Mur F, Ferrer-Ferrer M, Gelpi E, Pedragosa J, Justicia C, et al. Neutrophil recruitment to the brain in mouse and human ischemic stroke. Acta Neuropathol. (2015) 129:239-57. doi: 10.1007/s00401-014-1381-0

26. Mildner A, Marinkovic G, Jung S. Murine monocytes: origins, subsets, fates, and functions. Microbiol Spectr. (2016) 4:1-11. doi: 10.1128/microbiolspec.MCHD-0033-201

27. Yang J, Zhang L, Yu C, Yang XF, Wang H. Monocyte and macrophage differentiation: circulation inflammatory monocyte as biomarker for inflammatory diseases. Biomark Res. (2014) 2:1. doi: 10.1186/2050-7771-2-1

28. Geissmann F, Jung S, Littman DR. Blood monocytes consist of two principal subsets with distinct migratory properties. Immunity. (2003) 19:71-82. doi: 10.1016/S1074-7613(03)00174-2

29. Sunderkotter C, Nikolic T, Dillon MJ, Van Rooijen N, Stehling M, Drevets DA, et al. Subpopulations of mouse blood monocytes differ in maturation stage and inflammatory response. J Immunol. (2004) 172:4410-7. doi: 10.4049/jimmunol.172.7.4410

30. Thomas G, Tacke R, Hedrick CC, Hanna RN. Nonclassical patrolling monocyte function in the vasculature. Arterioscler Thromb Vasc Biol. (2015) 35:1306-16. doi: 10.1161/ATVBAHA.114.304650

31. Williams DL, Li C, Sherwood ER. Loss of monocyte metabolic plasticity in endotoxin tolerance: a model for understanding sepsis-induced immune paralysis? J Leukoc Biol. (2019) 106:7-9. doi: 10.1002/JLB.4CE0319-100R

32. Gautier EL, Shay T, Miller J, Greter M, Jakubzick C, Ivanov S, et al. Gene expression profiles and transcriptional regulatory pathways that underlie the identity and diversity of mouse tissue macrophages. Nat Immunol. (2012) 13:1118-28. doi: 10.1038/ni.2419

33. Gordon S. Targeting a monocyte subset to reduce inflammation. Circ Res. (2012) 110:1546-8. doi: 10.1161/RES.0b013e31825ec26d

34. Fani Maleki A, Cisbani G, Plante MM, Prefontaine P, Laflamme N, Gosselin $\mathrm{J}$, et al. Muramyl dipeptide-mediated immunomodulation on monocyte subsets exerts therapeutic effects in a mouse model of Alzheimer's disease. J Neuroinflammation. (2020) 17:218. doi: 10.1186/s12974-020-01893-3 
35. Huang QQ, Birkett R, Doyle R, Shi B, Roberts EL, Mao Q, et al. The role of macrophages in the response to TNF inhibition in experimental arthritis. $J$ Immunol. (2018) 200:130-8. doi: 10.4049/jimmunol.1700229

36. Arterbery AS, Osafo-Addo A, Avitzur Y, Ciarleglio M, Deng Y, Lobritto SJ, et al. Production of proinflammatory cytokines by monocytes in livertransplanted recipients with de novo autoimmune hepatitis is enhanced and induces TH1-like regulatory T cells. J Immunol. (2016) 196:4040-51. doi: $10.4049 /$ jimmunol.1502276

37. Hosaka K, Rojas K, Fazal HZ, Schneider MB, Shores J, Federico V, et al. Monocyte Chemotactic protein-1-interleukin-6-osteopontin pathway of intra-aneurysmal tissue healing. Stroke. (2017) 48:1052-60. doi: 10.1161/STROKEAHA.116.015590

38. Das A, Sinha M, Datta S, Abas M, Chaffee S, Sen CK, et al. Monocyte and macrophage plasticity in tissue repair and regeneration. Am J Pathol. (2015) 185:2596-606. doi: 10.1016/j.ajpath.2015.06.001

39. Prasse A, Germann M, Pechkovsky DV, Markert A, Verres T, Stahl M, et al. IL-10-producing monocytes differentiate to alternatively activated macrophages and are increased in atopic patients. J Allergy Clin Immunol. (2007) 119:464-71. doi: 10.1016/j.jaci.2006.09.030

40. Borthwick LA, Barron L, Hart KM, Vannella KM, Thompson RW, Oland S, et al. Macrophages are critical to the maintenance of IL-13dependent lung inflammation and fibrosis. Mucosal Immunol. (2016) 9:3855. doi: $10.1038 / \mathrm{mi} .2015 .34$

41. Nair MG, Guild KJ, Artis D. Novel effector molecules in type 2 inflammation: lessons drawn from helminth infection and allergy. J Immunol. (2006) 177:1393-9. doi: 10.4049/jimmunol.177.3.1393

42. Arnold L, Henry A, Poron F, Baba-Amer Y, van Rooijen N, Plonquet A, et al. Inflammatory monocytes recruited after skeletal muscle injury switch into antiinflammatory macrophages to support myogenesis. J Exp Med. (2007) 204:1057-69. doi: 10.1084/jem.20070075

43. Auffray C, Fogg D, Garfa M, Elain G, Join-Lambert O, Kayal S, et al. Monitoring of blood vessels and tissues by a population of monocytes with patrolling behavior. Science. (2007) 317:666-70. doi: $10.1126 /$ science. 1142883

44. Nguyen KD, Qiu Y, Cui X, Goh YP, Mwangi J, David T, et al. Alternatively activated macrophages produce catecholamines to sustain adaptive thermogenesis. Nature. (2011) 480:104-8. doi: 10.1038/nature10653

45. Yeh CF, Chuang TY, Hung YW, Lan MY, Tsai CH, Huang $\mathrm{HX}$, et al. Inhibition of soluble epoxide hydrolase regulates monocyte/macrophage polarization and improves neurological outcome in a rat model of ischemic stroke. Neuroreport. (2019) 30:567-72. doi: 10.1097/WNR.0000000000001248

46. Kao JK, Wang SC, Ho LW, Huang SW, Lee CH, Lee MS, et al. M2-like polarization of THP-1 monocyte-derived macrophages under chronic iron overload. Ann Hematol. (2020) 99:431-41. doi: 10.1007/s00277-020-03916-8

47. Chawla A. Control of macrophage activation and function by PPARs. Circ Res. (2010) 106:1559-69. doi: 10.1161/CIRCRESAHA.110.216523

48. Toor IS, Ruckerl D, Mair I, Thomson A, Rossi AG, Newby DE, et al. Enhanced monocyte recruitment and delayed alternative macrophage polarization accompanies impaired repair following myocardial infarction in C57BL/6 compared to BALB/c mice. Clin Exp Immunol. (2019) 198:83-93. doi: $10.1111 /$ cei.13330

49. Rao Muvva J, Parasa VR, Lerm M, Svensson M, Brighenti S. Polarization of human monocyte-derived cells with vitamin D promotes control of Mycobacterium tuberculosis infection. Front Immunol. (2019) 10:3157. doi: 10.3389/fimmu.2019.03157

50. Gomez Perdiguero E, Klapproth K, Schulz C, Busch K, Azzoni E, Crozet L, et al. Tissue-resident macrophages originate from yolk-sac-derived erythromyeloid progenitors. Nature. (2015) 518:547-51. doi: 10.1038/nature13989

51. Schulz C, Gomez Perdiguero E, Chorro L, Szabo-Rogers H, Cagnard $\mathrm{N}$, Kierdorf $\mathrm{K}$, et al. A lineage of myeloid cells independent of Myb and hematopoietic stem cells. Science. (2012) 336:86-90. doi: $10.1126 /$ science. 1219179

52. Theriault P, ElAli A, Rivest S. The dynamics of monocytes and microglia in Alzheimer's disease. Alzheimers Res Ther. (2015) 7:41. doi: $10.1186 / \mathrm{s} 13195-015-0125-2$
53. Auffray C, Sieweke MH, Geissmann F. Blood monocytes: development, heterogeneity, and relationship with dendritic cells. Annu Rev Immunol. (2009) 27:669-92. doi: 10.1146/annurev.immunol.021908.132557

54. Mildner A, Yona S, Jung S. A close encounter of the third kind: monocyte-derived cells. Adv Immunol. (2013) 120:69-103. doi: 10.1016/B978-0-12-417028-5.00003-X

55. Bain CC, Hawley CA, Garner H, Scott CL, Schridde A, Steers NJ, et al. Longlived self-renewing bone marrow-derived macrophages displace embryoderived cells to inhabit adult serous cavities. Nat Commun. (2016) 7:11852. doi: 10.1038/ncomms 11852

56. Molawi K, Wolf Y, Kandalla PK, Favret J, Hagemeyer N, Frenzel K, et al. Progressive replacement of embryo-derived cardiac macrophages with age. $J$ Exp Med. (2014) 211:2151-8. doi: 10.1084/jem.20140639

57. Varol C, Landsman L, Fogg DK, Greenshtein L, Gildor B, Margalit R, et al. Monocytes give rise to mucosal, but not splenic, conventional dendritic cells. J Exp Med. (2007) 204:171-80. doi: 10.1084/jem.20061011

58. Yona S, Kim KW, Wolf Y, Mildner A, Varol D, Breker M, et al. Fate mapping reveals origins and dynamics of monocytes and tissue macrophages under homeostasis. Immunity. (2013) 38:79-91. doi: 10.1016/j.immuni.2012.12.001

59. Alder JK, Georgantas RW 3rd, Hildreth RL, Kaplan IM, Morisot S, Yu X, et al. Kruppel-like factor 4 is essential for inflammatory monocyte differentiation in vivo. J Immunol. (2008) 180:5645-52. doi: 10.4049/jimmunol.180.8.5645

60. Tsou CL, Peters W, Si Y, Slaymaker S, Aslanian AM, Weisberg SP, et al. Critical roles for CCR2 and MCP-3 in monocyte mobilization from bone marrow and recruitment to inflammatory sites. J Clin Invest. (2007) 117:9029. doi: 10.1172/JCI29919

61. Faustino J, Chip S, Derugin N, Jullienne A, Hamer M, Haddad E, et al. CX3CR1-CCR2-dependent monocyte-microglial signaling modulates neurovascular leakage and acute injury in a mouse model of childhood stroke. J Cereb Blood Flow Metab. (2019) 39:1919-35. doi: 10.1177/0271678X18817663

62. Jiang W, St-Pierre S, Roy P, Morley BJ, Hao J, Simard AR. Infiltration of CCR2+Ly6Chigh proinflammatory monocytes and neutrophils into the central nervous system is modulated by nicotinic acetylcholine receptors in a model of multiple sclerosis. J Immunol. (2016) 196:2095-108. doi: 10.4049/jimmunol.1501613

63. Zouggari Y, Ait-Oufella H, Bonnin P, Simon T, Sage AP, Guerin C, et al. B lymphocytes trigger monocyte mobilization and impair heart function after acute myocardial infarction. Nat Med. (2013) 19:1273-80. doi: $10.1038 / \mathrm{nm} .3284$

64. Carlin LM, Stamatiades EG, Auffray C, Hanna RN, Glover L, VizcayBarrena G, et al. Nr4a1-dependent Ly6C(low) monocytes monitor endothelial cells and orchestrate their disposal. Cell. (2013) 153:362-75. doi: 10.1016/j.cell.2013.03.010

65. Kurotaki D, Osato N, Nishiyama A, Yamamoto M, Ban T, Sato $H$, et al. Essential role of the IRF8-KLF4 transcription factor cascade in murine monocyte differentiation. Blood. (2013) 121:1839-49. doi: 10.1182/blood-2012-06-437863

66. Kurotaki D, Sasaki H, Tamura T. Transcriptional control of monocyte and macrophage development. Int Immunol. (2017) 29:97-107. doi: 10.1093/intimm/dxx016

67. Kueh HY, Champhekar A, Nutt SL, Elowitz MB, Rothenberg EV. Positive feedback between PU.1 and the cell cycle controls myeloid differentiation. Science. (2013) 341:670-3. doi: 10.1126/science.1240831

68. Kurotaki D, Tamura T. Transcriptional and epigenetic regulation of innate immune cell development by the transcription factor, interferon regulatory factor-8. J Interferon Cytokine Res. (2016) 36:433-41. doi: 10.1089/jir.2015.0138

69. Hanna RN, Carlin LM, Hubbeling HG, Nackiewicz D, Green AM, Punt JA, et al. The transcription factor NR4A1 (Nur77) controls bone marrow differentiation and the survival of Ly6C- monocytes. Nat Immunol. (2011) 12:778-85. doi: 10.1038/ni.2063

70. Mildner A, Schonheit J, Giladi A, David E, Lara-Astiaso D, Lorenzo-Vivas $\mathrm{E}$, et al. Genomic characterization of murine monocytes reveals C/EBPbeta transcription factor dependence of Ly6C(-) cells. Immunity. (2017) 46:84962.e7. doi: 10.1016/j.immuni.2017.04.018 
71. Dounousi E, Duni A, Naka KK, Vartholomatos G, Zoccali C. The innate immune system and cardiovascular disease in Eskd: monocytes and natural killer cells. Curr Vasc Pharmacol. (2020) 18. doi: 10.2174/1570161118666200628024027

72. Hudson CA, Burack WR, Leary PC, Bennett JM. Clinical utility of classical and nonclassical monocyte percentage in the diagnosis of chronic myelomonocytic leukemia. Am J Clin Pathol. (2018) 150:293-302. doi: 10.1093/ajcp/aqy054

73. Shalova IN, Lim JY, Chittezhath M, Zinkernagel AS, Beasley F, HernandezJimenez E, et al. Human monocytes undergo functional re-programming during sepsis mediated by hypoxia-inducible factor-1alpha. Immunity. (2015) 42:484-98. doi: 10.1016/j.immuni.2015.02.001

74. Glezeva N, Horgan S, Baugh JA. Monocyte and macrophage subsets along the continuum to heart failure: misguided heroes or targetable villains? J Mol Cell Cardiol. (2015) 89:136-45. doi: 10.1016/j.yjmcc.2015.10.029

75. Matsumoto K, Suzuki K, Yoshimoto K, Seki N, Tsujimoto H, Chiba $\mathrm{K}$, et al. Longitudinal immune cell monitoring identified $\mathrm{CD} 14^{++}$ $\mathrm{CD}_{16}{ }^{+}$intermediate monocyte as a marker of relapse in patients with ANCA-associated vasculitis. Arthritis Res Ther. (2020) 22:145. doi: 10.1186/s13075-020-02234-8

76. Treiber T, Treiber N, Meister G. Regulation of microRNA biogenesis and its crosstalk with other cellular pathways. Nat Rev Mol Cell Biol. (2019) 20:5-20. doi: 10.1038/s41580-018-0059-1

77. Self-Fordham JB, Naqvi AR, Uttamani JR, Kulkarni V, Nares S. MicroRNA: dynamic regulators of macrophage polarization and plasticity. Front Immunol. (2017) 8:1062. doi: 10.3389/fimmu.2017.01062

78. Etzrodt M, Cortez-Retamozo V, Newton A, Zhao J, Ng A, Wildgruber M, et al. Regulation of monocyte functional heterogeneity by miR-146a and Relb. Cell Rep. (2012) 1:317-24. doi: 10.1016/j.celrep.2012.02.009

79. Zhao JL, Rao DS, O'Connell RM, Garcia-Flores Y, Baltimore D. MicroRNA$146 \mathrm{a}$ acts as a guardian of the quality and longevity of hematopoietic stem cells in mice. Elife. (2013) 2:e00537. doi: 10.7554/eLife.00537

80. Duroux-Richard I, Robin M, Peillex C, Apparailly F. MicroRNAs: fine tuners of monocyte heterogeneity. Front Immunol. (2019) 10:2145. doi: 10.3389/fimmu.2019.02145

81. Frankenberger M, Hofer TP, Marei A, Dayyani F, Schewe S, Strasser C, et al. Transcript profiling of CD16-positive monocytes reveals a unique molecular fingerprint. Eur J Immunol. (2012) 42:957-74. doi: 10.1002/eji.2011 41907

82. Dang TM, Wong WC, Ong SM, Li P, Lum J, Chen J, et al. MicroRNA expression profiling of human blood monocyte subsets highlights functional differences. Immunology. (2015) 145:404-16. doi: 10.1111/imm.12456

83. Zawada AM, Schneider JS, Michel AI, Rogacev KS, Hummel B, Krezdorn N, et al. DNA methylation profiling reveals differences in the 3 human monocyte subsets and identifies uremia to induce DNA methylation changes during differentiation. Epigenetics. (2016) 11:259-72. doi: 10.1080/15592294.2016.1158363

84. Chipont A, Esposito B, Challier I, Montabord M, Tedgui A, Mallat $\mathrm{Z}$, et al. MicroRNA-21 deficiency alters the survival of Ly-6C(lo) monocytes in $\operatorname{ApoE}(-/-)$ mice and reduces early-stage atherosclerosisbrief report. Arterioscler Thromb Vasc Biol. (2019) 39:170-7. doi: 10.1161/ATVBAHA.118.311942

85. Selimoglu-Buet D, Riviere J, Ghamlouch H, Bencheikh L, Lacout C, Morabito $\mathrm{M}$, et al. A miR-150/TET3 pathway regulates the generation of mouse and human non-classical monocyte subset. Nat Commun. (2018) 9:5455. doi: 10.1038/s41467-018-07801-x

86. Guruswamy R, ElAli A. Complex roles of microglial cells in ischemic stroke pathobiology: new insights and future directions. Int J Mol Sci. (2017) 18:496. doi: 10.3390/ijms 18030496

87. Fumagalli S, Perego C, Pischiutta F, Zanier ER, De Simoni MG. The ischemic environment drives microglia and macrophage function. Front Neurol. (2015) 6:81. doi: 10.3389/fneur.2015.00081

88. Zhao SC, Ma LS, Chu ZH, Xu H, Wu WQ, Liu F. Regulation of microglial activation in stroke. Acta Pharmacol Sin. (2017) 38:445-58. doi: 10.1038/aps.2016.162

89. Jin WN, Shi SX, Li Z, Li M, Wood K, Gonzales RJ, et al. Depletion of microglia exacerbates postischemic inflammation and brain injury. J Cereb Blood Flow Metab. (2017) 37:2224-36. doi: 10.1177/0271678X17694185
90. Szalay G, Martinecz B, Lenart N, Kornyei Z, Orsolits B, Judak L, et al. Microglia protect against brain injury and their selective elimination dysregulates neuronal network activity after stroke. Nat Commun. (2016) 7:11499. doi: 10.1038/ncomms11499

91. Kim BJ, Kim MJ, Park JM, Lee SH, Kim YJ, Ryu S, et al. Reduced neurogenesis after suppressed inflammation by minocycline in transient cerebral ischemia in rat. J Neurol Sci. (2009) 279:70-5. doi: 10.1016/j.jns.2008.12.025

92. Faustino JV, Wang X, Johnson CE, Klibanov A, Derugin N, Wendland MF, et al. Microglial cells contribute to endogenous brain defenses after acute neonatal focal stroke. J Neurosci. (2011) 31:12992-3001. doi: 10.1523/JNEUROSCI.2102-11.2011

93. Ritzel RM, Patel AR, Grenier JM, Crapser J, Verma R, Jellison ER, et al. Functional differences between microglia and monocytes after ischemic stroke. J Neuroinflammation. (2015) 12:106. doi: 10.1186/s12974-015-0329-1

94. Sun M, Deng B, Zhao X, Gao C, Yang L, Zhao H, et al. Isoflurane preconditioning provides neuroprotection against stroke by regulating the expression of the TLR4 signalling pathway to alleviate microglial activation. Sci Rep. (2015) 5:11445. doi: 10.1038/srep11445

95. Losy J, Zaremba J. Monocyte chemoattractant protein-1 is increased in the cerebrospinal fluid of patients with ischemic stroke. Stroke. (2001) 32:26956. doi: 10.1161/hs1101.097380

96. Mo X, Li T, Ji G, Lu W, Hu Z. Peripheral polymorphonuclear leukocyte activation as a systemic inflammatory response in ischemic stroke. Neurol Sci. (2013) 34:1509-16. doi: 10.1007/s10072-013-1447-0

97. Ley K, Laudanna C, Cybulsky MI, Nourshargh S. Getting to the site of inflammation: the leukocyte adhesion cascade updated. Nat Rev Immunol. (2007) 7:678-89. doi: 10.1038/nri2156

98. Pedragosa J, Miro-Mur F, Otxoa-de-Amezaga A, Justicia C, Ruiz-Jaen F, Ponsaerts $\mathrm{P}$, et al. CCR2 deficiency in monocytes impairs angiogenesis and functional recovery after ischemic stroke in mice. J Cereb Blood Flow Metab. (2020) 1-19. doi: 10.1177/0271678X20909055

99. Fang W, Zhai X, Han D, Xiong X, Wang T, Zeng X, et al. CCR2dependent monocytes/macrophages exacerbate acute brain injury but promote functional recovery after ischemic stroke in mice. Theranostics. (2018) 8:3530-43. doi: 10.7150/thno.24475

100. Choi DJ, Yang H, Gaire S, Lee KA, An J, Kim BG, et al. Critical roles of astrocytic-CCL2-dependent monocyte infiltration in a DJ-1 knockout mouse model of delayed brain repair. Glia. (2020) 68:2086-101. doi: 10.1002/glia.23828

101. Howe CL, LaFrance-Corey RG, Goddery EN, Johnson RK, Mirchia K. Neuronal CCL2 expression drives inflammatory monocyte infiltration into the brain during acute virus infection. J Neuroinflammation. (2017) 14:238. doi: 10.1186/s12974-017-1015-2

102. Georgakis MK, Malik R, Bjorkbacka H, Pana TA, Demissie S, Ayers C, et al. Circulating monocyte chemoattractant protein-1 and risk of stroke: metaanalysis of population-based studies involving 17180 individuals. Circ Res. (2019) 125:773-82. doi: 10.1161/CIRCRESAHA.119.315380

103. Planas AM. Role of immune cells migrating to the ischemic brain. Stroke. (2018) 49:2261-7. doi: 10.1161/STROKEAHA.118.021474

104. Yang J, Balkaya M, Beltran C, Heo JH, Cho S. Remote postischemic conditioning promotes stroke recovery by shifting circulating monocytes to $\mathrm{CCR}^{+}$proinflammatory subset. J Neurosci. (2019) 39:7778-89. doi: 10.1523/JNEUROSCI.2699-18.2019

105. Wattananit S, Tornero D, Graubardt N, Memanishvili T, Monni E, Tatarishvili J, et al. Monocyte-derived macrophages contribute to spontaneous long-term functional recovery after stroke in mice. J Neurosci. (2016) 36:4182-95. doi: 10.1523/JNEUROSCI.4317-15.2016

106. Perego C, Fumagalli S, Zanier ER, Carlino E, Panini N, Erba E, et al. Macrophages are essential for maintaining a M2 protective response early after ischemic brain injury. Neurobiol Dis. (2016) 96:284-93. doi: 10.1016/j.nbd.2016.09.017

107. Kronenberg G, Uhlemann R, Richter N, Klempin F, Wegner S, Staerck $\mathrm{L}$, et al. Distinguishing features of microglia- and monocyte-derived macrophages after stroke. Acta Neuropathol. (2018) 135:551-68. doi: 10.1007/s00401-017-1795-6

108. Tanaka R, Komine-Kobayashi M, Mochizuki H, Yamada M, Furuya T, Migita M, et al. Migration of enhanced green fluorescent protein expressing bone marrow-derived microglia/macrophage into the mouse 
brain following permanent focal ischemia. Neuroscience. (2003) 117:531-9. doi: 10.1016/S0306-4522(02)00954-5

109. Fan Y, Xiong X, Zhang Y, Yan D, Jian Z, Xu B, et al. MKEY, a peptide inhibitor of CXCL4-CCL5 heterodimer formation, protects against stroke in mice. $J$ Am Heart Assoc. (2016) 5:e003615. doi: 10.1161/JAHA.116.003615

110. Selvaraj UM, Ortega SB, Hu R, Gilchrist R, Kong X, Partin A, et al. Preconditioning-induced CXCL12 upregulation minimizes leukocyte infiltration after stroke in ischemia-tolerant mice. J Cereb Blood Flow Metab. (2017) 37:801-13. doi: 10.1177/0271678X16639327

111. Lee M, Lee Y, Song J, Lee J, Chang SY. Tissue-specific role of CX3CR1 expressing immune cells and their relationships with human disease. Immune Netw. (2018) 18:e5. doi: 10.4110/in.2018.18.e5

112. Michaud JP, Pimentel-Coelho PM, Tremblay Y, Rivest S. The impact of Ly6Clow monocytes after cerebral hypoxia-ischemia in adult mice. J Cereb Blood Flow Metab. (2014) 34:e1-9. doi: 10.1038/jcbfm.2014.80

113. Meghraoui-Kheddar A, Barthelemy S, Boissonnas A, Combadiere C. Revising CX3CR1 expression on murine classical and non-classical monocytes. Front Immunol. (2020) 11:1117. doi: 10.3389/fimmu.2020.01117

114. ElAli A, Jean LeBlanc N. The role of monocytes in ischemic stroke pathobiology: new avenues to explore. Front Aging Neurosci. (2016) 8:29. doi: 10.3389/fnagi.2016.00029

115. Chauhan A, Hudobenko J, Al Mamun A, Koellhoffer EC, Patrizz A, Ritzel RM, et al. Myeloid-specific TAK1 deletion results in reduced brain monocyte infiltration and improved outcomes after stroke. J Neuroinflammation. (2018) 15:148. doi: 10.1186/s12974-018-1188-3

116. Werner Y, Mass E, Ashok Kumar P, Ulas T, Handler K, Horne A, et al. Cxcr4 distinguishes HSC-derived monocytes from microglia and reveals monocyte immune responses to experimental stroke. Nat Neurosci. (2020) 23:351-62. doi: 10.1038/s41593-020-0585-y

117. Gliem M, Mausberg AK, Lee JI, Simiantonakis I, van Rooijen N, Hartung HP, et al. Macrophages prevent hemorrhagic infarct transformation in murine stroke models. Ann Neurol. (2012) 71:743-52. doi: 10.1002/ana.23529

118. Park JH. Microglia/Macrophages dynamics on neuroinflammatory responses in the model of cerebral ischemia [dissertation]. Yonsei University, Seoul, South Korea (2020).

119. Jakubzick C, Gautier EL, Gibbings SL, Sojka DK, Schlitzer A, Johnson TE, et al. Minimal differentiation of classical monocytes as they survey steady-state tissues and transport antigen to lymph nodes. Immunity. (2013) 39:599-610. doi: 10.1016/j.immuni.2013.08.007

120. Mitka M. Early treatment of ischemic stroke with intravenous tPA reduces disability risk. JAMA. (2013) 310:1111. doi: 10.1001/jama.2013.278292

121. Zerna C, Thomalla G, Campbell BCV, Rha JH, Hill MD. Current practice and future directions in the diagnosis and acute treatment of ischaemic stroke. Lancet. (2018) 392:1247-56. doi: 10.1016/S0140-6736(18)31874-9

122. Pandian JD, Gall SL, Kate MP, Silva GS, Akinyemi RO, Ovbiagele BI, et al. Prevention of stroke: a global perspective. Lancet. (2018) 392:1269-78. doi: 10.1016/S0140-6736(18)31269-8

123. Khandelwal P, Yavagal DR, Sacco RL. Acute ischemic stroke intervention. $J$ Am Coll Cardiol. (2016) 67:2631-44. doi: 10.1016/j.jacc.2016.03.555

124. Kitagawa K, Hosomi N, Nagai Y, Kagimura T, Ohtsuki T, Maruyama H, et al. Cumulative effects of LDL cholesterol and CRP levels on recurrent stroke and TIA. J Atheroscler Thromb. (2019) 26:432-41. doi: 10.5551/jat.45989

125. Zhu Z, Xu T, Guo D, Huangfu X, Zhong C, Yang J, et al. Serum hepatocyte growth factor is probably associated with 3-month prognosis of acute ischemic stroke. Stroke. (2018) 49:377-83. doi: 10.1161/STROKEAHA.117.019476

126. Armbrust M, Worthmann H, Dengler R, Schumacher H, Lichtinghagen $\mathrm{R}$, Eschenfelder CC, et al. Circulating insulin-like growth factor-1 and insulin-like growth factor binding protein-3 predict three-months outcome after ischemic stroke. Exp Clin Endocrinol Diabetes. (2017) 125:485-91. doi: 10.1055/s-0043-103965

127. Szekely EG, Czuriga-Kovacs KR, Bereczky Z, Katona E, Mezei ZA, Nagy A, et al. Low factor XIII levels after intravenous thrombolysis predict short-term mortality in ischemic stroke patients. Sci Rep. (2018) 8:7662. doi: 10.1038/s41598-018-26025-z

128. Mourao AM, Vicente LCC, Abreu MNS, Vale Sant'Anna R, Vieira ELM, de Souza LC, et al. Plasma levels of brain-derived neurotrophic factor are associated with prognosis in the acute phase of ischemic stroke. J Stroke Cerebrovasc Dis. (2019) 28:735-40. doi: 10.1016/j.jstrokecerebrovasdis.2018.11.013

129. Hamatani Y, Nagai T, Nakai M, Nishimura K, Honda Y, Nakano H, et al. Elevated plasma D-dimer level is associated with short-term risk of ischemic stroke in patients with acute heart failure. Stroke. (2018) 49:1737-40. doi: 10.1161/STROKEAHA.118.021899

130. Liu H, Liu K, Pei L, Gao Y, Zhao L, Sun S, et al. Monocyte-to-high-density lipoprotein ratio predicts the outcome of acute ischemic stroke. J Atheroscler Thromb. (2020) 57:959-68. doi: 10.5551/jat.51151

131. Wang CW, Ma PJ, Wang YY, Yang M, Su LL, Wang S, et al. Serum level of macrophage migration inhibitory factor predicts severity and prognosis in patients with ischemic stroke. Cytokine. (2019) 115:8-12. doi: 10.1016/j.cyto.2018.11.029

132. Ren H, Liu X, Wang L, Gao Y. Lymphocyte-to-monocyte ratio: a novel predictor of the prognosis of acute ischemic stroke. J Stroke Cerebrovasc Dis. (2017) 26:2595-602. doi: 10.1016/j.jstrokecerebrovasdis.2017.06.019

133. Song Q, Pan R, Jin Y, Wang Y, Cheng Y, Liu J, et al. Lymphocyte-to-monocyte ratio and risk of hemorrhagic transformation in patients with acute ischemic stroke. Neurol Sci. (2020) 41:2511-20. doi: 10.1007/s10072-020-04355-Z

134. Ye Z, Jin $\mathrm{Y}, \mathrm{Li} \mathrm{H}, \mathrm{Xu} \mathrm{H}, \mathrm{He} \mathrm{Y}$, Chen Y. Association of tim-4 expression in monocyte subtypes with clinical course and prognosis in acute ischemic stroke patients. Int J Neurosci. (2020) 130:909-16. doi: 10.1080/00207454.2019.1709842

135. Kim YJ, Gallien S, van Oostrum J, Domon B. Targeted proteomics strategy applied to biomarker evaluation. Proteomics Clin Appl. (2013) 7:739-47. doi: $10.1002 /$ prca. 201300070

136. Ostolaza A, Blanco-Luquin I, Urdanoz-Casado A, Rubio I, Labarga A, Zandio B, et al. Circular RNA expression profile in blood according to ischemic stroke etiology. Cell Biosci. (2020) 10:34. doi: 10.1186/s13578-020-00394-3

137. Chiesa M, Piacentini L, Bono E, Milazzo V, Campodonico J, Marenzi $\mathrm{G}$, et al. Whole blood transcriptome profile at hospital admission discriminates between patients with ST-segment elevation and non-STsegment elevation acute myocardial infarction. Sci Rep. (2020) 10:8731. doi: 10.1038/s41598-020-65527-7

138. Zuo Z, Hu H, Xu Q, Luo X, Peng D, Zhu K, et al. BBCancer: an expression atlas of blood-based biomarkers in the early diagnosis of cancers. Nucleic Acids Res. (2020) 48:D789-96. doi: 10.1093/nar/gkz942

139. Cox-Limpens KE, Gavilanes AW, Zimmermann LJ, Vles JS. Endogenous brain protection: what the cerebral transcriptome teaches us. Brain Res. (2014) 1564:85-100. doi: 10.1016/j.brainres.2014.04.001

140. Ramsay L, Quille ML, Orset C, de la Grange P, Rousselet E, Ferec C, et al. Blood transcriptomic biomarker as a surrogate of ischemic brain gene expression. Ann Clin Transl Neurol. (2019) 6:1681-95. doi: $10.1002 / \operatorname{acn} 3.50861$

141. Stamova B, Ander BP, Jickling G, Hamade F, Durocher M, Zhan X, et al. The intracerebral hemorrhage blood transcriptome in humans differs from the ischemic stroke and vascular risk factor control blood transcriptomes. J Cereb Blood Flow Metab. (2019) 39:1818-35. doi: 10.1177/0271678X18769513

142. Wang R, Liu Y, Ye Q, Hassan SH, Zhao J, Li S, et al. RNA sequencing reveals novel macrophage transcriptome favoring neurovascular plasticity after ischemic stroke. J Cereb Blood Flow Metab. (2020) 40:720-38. doi: $10.1177 / 0271678 X 19888630$

143. Houben E, Hellings N, Broux B. Oncostatin M, an underestimated player in the central nervous system. Front Immunol. (2019) 10:1165. doi: $10.3389 /$ fimmu.2019.01165

144. Zhu Q, Luo X, Zhang J, Liu Y, Luo H, Huang Q, et al. Osteopontin as a potential therapeutic target for ischemic stroke. Curr Drug Deliv. (2017) 14:766-72. doi: 10.2174/1567201814666161116162148

145. Groschel K, Schnaudigel S, Edelmann F, Niehaus CF, Weber-Kruger $M$, Haase B, et al. Growth-differentiation factor-15 and functional outcome after acute ischemic stroke. J Neurol. (2012) 259:1574-9. doi: 10.1007/s00415-011-6379-0

146. Hatakeyama M, Ninomiya I, Kanazawa M. Angiogenesis and neuronal remodeling after ischemic stroke. Neural Regen Res. (2020) 15:16-9. doi: 10.4103/1673-5374.264442

147. Zou Y, Hu J, Huang W, Ye S, Han F, Du J, et al. Non-mitogenic fibroblast growth factor 1 enhanced angiogenesis following ischemic stroke 
by regulating the sphingosine-1-phosphate 1 pathway. Front Pharmacol. (2020) 11:59. doi: 10.3389/fphar.2020.00059

148. Zhang W, Zhao J, Wang R, Jiang M, Ye Q, Smith AD, et al. Macrophages reprogram after ischemic stroke and promote efferocytosis and inflammation resolution in the mouse brain. CNS Neurosci Ther. (2019) 25:1329-42. doi: $10.1111 / \mathrm{cns} .13256$

149. Yang H, Graham LC, Reagan AM, Grabowska WA, Schott WH, Howell GR. Transcriptome profiling of brain myeloid cells revealed activation of Itgal, Trem1, and Spp1 in western diet-induced obesity. J Neuroinflammation. (2019) 16:169. doi: 10.1186/s12974-019-1527-z

150. Heo KS, Cushman HJ, Akaike M, Woo CH, Wang X, Qiu X, et al. ERK5 activation in macrophages promotes efferocytosis and inhibits atherosclerosis. Circulation. (2014) 130:180-91. doi: 10.1161/CIRCULATIONAHA.113.005991

151. Schilling M, Strecker JK, Ringelstein EB, Schabitz WR, Kiefer R. The role of CC chemokine receptor 2 on microglia activation and blood-borne cell recruitment after transient focal cerebral ischemia in mice. Brain Res. (2009) 1289:79-84. doi: 10.1016/j.brainres.2009.06.054

152. Dimitrijevic OB, Stamatovic SM, Keep RF, Andjelkovic AV. Absence of the chemokine receptor CCR2 protects against cerebral ischemia/reperfusion injury in mice. Stroke. (2007) 38:1345-53. doi: 10.1161/01.STR.0000259709.16654.8f

153. Ishizuka T, Niwa A, Tabuchi M, Ooshima K, Higashino H. Acetylsalicylic acid provides cerebrovascular protection from oxidant damage in salt-loaded stroke-prone rats. Life Sci. (2008) 82:806-15. doi: 10.1016/j.lfs.2008.01.017

154. Tymianski M. Aspirin as a promising agent for decreasing incidence of cerebral aneurysm rupture. Stroke. (2011) 42:3003-4. doi: 10.1161/STROKEAHA.111.626762

155. Liao JK. Rosuvastatin to prevent vascular events in men and women with elevated C-reactive protein. Curr Atheroscler Rep. (2009) 11:243-4. doi: 10.1007/s11883-009-0037-3

156. Ridker PM, Danielson E, Fonseca FA, Genest J, Gotto AM Jr., Kastelein $\mathrm{JJP}$, et al. Rosuvastatin to prevent vascular events in men and women with elevated C-reactive protein. N Engl J Med. (2008) 359:2195-207. doi: 10.1056/NEJMoa0807646

157. Sironi L, Gianazza E, Gelosa P, Guerrini U, Nobili E, Gianella A, et al. Rosuvastatin, but not simvastatin, provides end-organ protection in strokeprone rats by antiinflammatory effects. Arterioscler Thromb Vasc Biol. (2005) 25:598-603. doi: 10.1161/01.ATV.0000157145.98200.55

158. Vergouwen MD, de Haan RJ, Vermeulen M, Roos YB. Statin treatment and the occurrence of hemorrhagic stroke in patients with a history of cerebrovascular disease. Stroke. (2008) 39:497-502. doi: 10.1161/STROKEAHA.107.488791

159. White AT, Murphy AN. Administration of thiazolidinediones for neuroprotection in ischemic stroke: a pre-clinical systematic review. $J$ Neurochem. (2010) 115:845-53. doi: 10.1111/j.1471-4159.2010.06999.x

160. Nakamura T, Yamamoto E, Kataoka K, Yamashita T, Tokutomi Y, Dong YF, et al. Pioglitazone exerts protective effects against stroke in stroke-prone spontaneously hypertensive rats, independently of blood pressure. Stroke. (2007) 38:3016-22. doi: 10.1161/STROKEAHA.107.486522

161. Domercq M, Matute C. Neuroprotection by tetracyclines. Trends Pharmacol Sci. (2004) 25:609-12. doi: 10.1016/j.tips.2004.10.001

162. Thomas M, Le WD, Jankovic J. Minocycline and other tetracycline derivatives: a neuroprotective strategy in Parkinson's disease and Huntington's disease. Clin Neuropharmacol. (2003) 26:18-23. doi: 10.1097/00002826-200301000-00005

163. Yew WP, Djukic ND, Jayaseelan JSP, Walker FR, Roos KAA, Chataway TK, et al. Early treatment with minocycline following stroke in rats improves functional recovery and differentially modifies responses of peri-infarct microglia and astrocytes. J Neuroinflammation. (2019) 16:6. doi: 10.1186/s12974-018-1379-y

164. Flint AC, Avins AL, Eaton A, Uong S, Cullen SP, Hsu DP, et al. Risk of distal embolization from tPA (tissue-type plasminogen activator) administration prior to endovascular stroke treatment. Stroke. (2020) 51:2697-704. doi: 10.1161/STROKEAHA.120.029025

165. Jian Z, Liu R, Zhu X, Smerin D, Zhong Y, Gu L, et al. The involvement and therapy target of immune cells after ischemic stroke. Front Immunol. (2019) 10:2167. doi: 10.3389/fimmu.2019.02167
166. Jin R, Yang G, Li G. Inflammatory mechanisms in ischemic stroke: role of inflammatory cells. J Leukoc Biol. (2010) 87:779-89. doi: 10.1189/jlb.1109766

167. Lakhan SE, Kirchgessner A, Hofer M. Inflammatory mechanisms in ischemic stroke: therapeutic approaches. J Transl Med. (2009) 7:97. doi: 10.1186/1479-5876-7-97

168. Elkind MS, Cheng J, Rundek T, Boden-Albala B, Sacco RL. Leukocyte count predicts outcome after ischemic stroke: the northern Manhattan stroke study. J Stroke Cerebrovasc Dis. (2004) 13:220-7. doi: 10.1016/j.jstrokecerebrovasdis.2004.07.004

169. Gallacher KI, Jani BD, Hanlon P, Nicholl BI, Mair FS. Multimorbidity in stroke. Stroke. (2019) 50:1919-26. doi: 10.1161/STROKEAHA.118.020376

170. Zhang YJ, Song JR, Zhao MJ. NR4A1 regulates cerebral ischemiainduced brain injury by regulating neuroinflammation through interaction with NF-kappaB/p65. Biochem Biophys Res Commun. (2019) 518:59-65. doi: 10.1016/j.bbrc.2019.08.008

171. Fong WH, Tsai HD, Chen YC, Wu JS, Lin TN. Anti-apoptotic actions of PPAR-gamma against ischemic stroke. Mol Neurobiol. (2010) 41:180-6. doi: 10.1007/s12035-010-8103-y

172. Hilgendorf I, Gerhardt LM, Tan TC, Winter C, Holderried TA, Chousterman $\mathrm{BG}$, et al. Ly-6Chigh monocytes depend on Nr4al to balance both inflammatory and reparative phases in the infarcted myocardium. Circ Res. (2014) 114:1611-22. doi: 10.1161/CIRCRESAHA.114.303204

173. Motta BM, Pramstaller PP, Hicks AA, Rossini A. The impact of CRISPR/Cas9 technology on cardiac research: from disease modelling to therapeutic approaches. Stem Cells Int. (2017) 2017:8960236. doi: 10.1155/2017/8960236

174. Zhou YF, Li YN, Jin HJ, Wu JH, He QW, Wang XX, et al. Sema4D/PlexinB1 inhibition ameliorates blood-brain barrier damage and improves outcome after stroke in rats. FASEB J. (2018) 32:2181-96. doi: 10.1096/fj.201700786RR

175. Li M, Feng B, Wang L, Guo S, Zhang P, Gong J, et al. Tollip is a critical mediator of cerebral ischaemia-reperfusion injury. J Pathol. (2015) 237:24962. doi: $10.1002 /$ path. 4565

176. Landowski LM, Niego B, Sutherland BA, Hagemeyer CE, Howells DW. Applications of nanotechnology in the diagnosis and therapy of stroke. Semin Thromb Hemost. (2020) 46:592-605. doi: 10.1055/s-0039-3399568

177. Hou J, Yang X, Li S, Cheng Z, Wang Y, Zhao J, et al. Accessing neuroinflammation sites: monocyte/neutrophil-mediated drug delivery for cerebral ischemia. Sci Adv. (2019) 5:eaau8301. doi: 10.1126/sciadv.aau8301

178. Benedek A, Cernica D, Mester A, Opincariu D, Hodas R, Rodean I, et al. Modern concepts in regenerative therapy for ischemic stroke: from stem cells for promoting angiogenesis to 3D-bioprinted scaffolds customized via carotid shear stress analysis. Int J Mol Sci. (2019) 20:2574. doi: 10.3390/ijms20102574

179. Vijayavenkataraman S, Yan WC, Lu WF, Wang CH, Fuh JYH. 3D bioprinting of tissues and organs for regenerative medicine. Adv Drug Deliv Rev. (2018) 132:296-332. doi: 10.1016/j.addr.2018.07.004

180. Bracci R, Maccaroni E, Cascinu S. Transient sunitinib resistance in gastrointestinal stromal tumors. N Engl J Med. (2013) 368:2042-3. doi: 10.1056/NEJMc1301237

181. George PM, Bliss TM, Hua T, Lee A, Oh B, Levinson A, et al. Electrical preconditioning of stem cells with a conductive polymer scaffold enhances stroke recovery. Biomaterials. (2017) 142:31-40. doi: 10.1016/j.biomaterials.2017.07.020

182. Brzezinski M, Sejda A, Peksa R, Pawlak M, Bury K, Adamiak Z, et al. Evaluation of local tissue reaction after the application of a 3D printed novel holdfast device for left atrial appendage exclusion. Ann Biomed Eng. (2020) 48:133-43. doi: 10.1007/s10439-019-02320-2

Conflict of Interest: The authors declare that the research was conducted in the absence of any commercial or financial relationships that could be construed as a potential conflict of interest.

Copyright (c) 2020 Park, Chang, Kim and Lee. This is an open-access article distributed under the terms of the Creative Commons Attribution License (CC BY). The use, distribution or reproduction in other forums is permitted, provided the original author(s) and the copyright owner(s) are credited and that the original publication in this journal is cited, in accordance with accepted academic practice. No use, distribution or reproduction is permitted which does not comply with these terms. 


\section{GLOSSARY}

AIS, acute ischemic stroke; BBB, blood-brain barrier; BM, bone marrow; $\mathrm{BrdU}$, bromodeoxyuridine; CCL2, chemokine [CC motif] ligand 2; CCL7, chemokine [C-C motif] ligand 7; CCR2, C-C chemokine receptor 2; cMoP, common monocyte progenitors; CNS, central nervous system; CRP, C-reactive protein; CX3CL1, C-X3-C motif chemokine ligand 1; CX3CR1, C-X3-C motif chemokine receptor 1; CXCR4, C-X-C motif chemokine receptor 4; DCs, dendritic cell; $\mathrm{dMCAO}$, distal middle cerebral artery occlusion; ERK5, extracellular signal-regulated kinase 5; FGF1, fibroblast growth factor 1; HSCs, hematopoietic stem cells; HT-hemorrhagic transformation; IGF-1, insulin-like growth factor-1; IL-10, interleukin 10; IL-13, interleukin 13; IL-1b, interleukin-1 $\beta$; IL-4, interleukin-4; IL-6, interleukin-6; IRF8, interferon-regulatory factor 8; KLF4, kruppel-like factor 4;
LMR, lymphocyte-to-monocyte ratio; Ly6C, lymphocyte antigen 6C; M-CSF, macrophage colony stimulating factor; MCP-1, monocyte chemoattractant protein-1; MHR, monocyte-to-highdensity lipoprotein ratio; MIF, migration inhibitory factor; mKO, myeloid cell-specific PPAR $\gamma$ knockout; NIHSS, national institute of health stroke scale; NO, nitric oxide; NR4A1, nuclear receptor subfamily 4 group A member 1; Osm, oncostatin M; PPAR $\gamma$, peroxisome proliferator-activated receptor $\gamma$; RLC, remote ischemic limb conditioning; ROS, reactive oxygen species; S1PR1, S1P receptor 1; STAT6, signal transducer and activator of transcription 6; TAK1, transforming growth factor$\beta$-activated kinase 1; Tet3, Tet methylcytosine dioxygenase; TIM4 , T-cell immunoglobulin and mucin domain-4; TNF- $\alpha$, tumor necrosis factor- $\alpha$; tPA, tissue plasminogen activator; TREM1, triggering receptor expressed on myeloid cells 1; VEGF, vascular endothelial growth factor. 